\title{
MEASUREMENT AND PREDICTION OF RESIDUAL STRAINS AND STRESSES DURING THE COOLING OF A GLASS FIBRE REINFORCED PA66 MATRIX COMPOSITE
}

\author{
Mael Péron ${ }^{1,2, *}$, Frédéric Jacquemin ${ }^{1}$, Pascal Casari ${ }^{1}$, Gilles Orange ${ }^{3}$, Jérôme Bikard ${ }^{3}$, Jean-Luc \\ Bailleul $^{4}$, Nicolas Boyard ${ }^{4}$ \\ ${ }^{1}$ Université de Nantes, Institut de Recherche en Génie Civil et Mécanique (GeM) - UMR CNRS 6183 \\ Rue Michel Ange, 44600 Saint Nazaire, France \\ Email : mael.peron@univ-nantes.fr \\ ${ }^{2}$ IRT Jules Verne \\ Chemin du Chaffault, 44340 Bouguenais, France \\ ${ }^{3}$ Axel'One (Solvay) \\ 87 Avenue des Frères Perret, CS 70061, 69192 Saint Fons, France \\ ${ }^{4}$ Université de Nantes, Laboratoire de Thermique et Energie de Nantes (LTEN) - UMR CNRS 6607 \\ Rue Christian Pauc, CS 50609, 44306 Nantes CEDEX 3, France \\ *Corresponding Author. Email : mael.peron@univ-nantes.fr
}

\begin{abstract}
The forming process of thermoplastic composites inevitably leads to the development of residual stresses. This study proposes a model to predict the residual stresses at the ply level of a thermoplastic composite. It accounts for heat transfer, crystallization kinetics and the mechanical behaviour of the laminate. The model is applied to the cooling of a polyamide 66 (PA66) matrix reinforced with continuous glass fibres. The Stress Free Temperature is considered as the starting point of stresses accumulation within each ply. It is experimentally identified by monitoring the curvature evolution of composite coupons with temperature, leading to a temperature of $200^{\circ} \mathrm{C}$. The evolution of the curvatures
\end{abstract}


of $\left[90_{4} 0_{4}\right]$ laminates are recorded with a digital image correlation technique. They are compared with the curvatures predicted with the model, which permits to validate it. The predicted stresses distribution is then discussed, as well as the impact of several parameters on the stresses intensity.

Keywords: thermoplastic composite, residual stresses, thermomechanical, characterization, modeling

\section{Introduction}

Due to their ease of forming, their weldability, their recyclability and their higher resilience compared to thermoset composites, thermoplastic (TP) composites have shown to be very promising in the automotive industry for the manufacturing of structural parts [1]. Within this context, the TAPAS project (ThermoplAstic Process for Automotive Structure, ANR-11-RMNP-0020) aimed at developing a specific low viscosity PA66 and the associated Liquid Composite Molding (LCM) manufacturing process in order to produce continuous glass fiber reinforced PA66 composites for the automotive industry at a high manufacturing rate. The main goals of this project were to enhance the impregnation of the fibers during the process [2] and to precisely describe the heat transfer and crystallization kinetics during the cooling of the composite $[3,4]$. The evaluation of the thermomechanical behavior of the developed material and the associated process induced stresses was still to investigate and was performed within the COMPETH research project supported by the IRT Jules Verne. As the development of the thermomechanical properties of the material depend highly on the material microstructure, the crystallization and the temperature, the previous studies [2-4] appeared as mandatory to successfully predict the residual stresses during the cooling of the involved material.

Indeed, the intrinsic heterogeneity of TP composite materials and their high forming temperatures (e.g. around $260^{\circ} \mathrm{C}$ for a PA66) lead to the development of residual stresses. At the part scale, these stresses are partly due to the mismatch of the coefficients of thermal expansion along the principal directions of the different constitutive plies of the composite laminate [5]. They are thus emphasized by the wide temperature decrease during the cooling of TP composites. These stresses are also partly caused by the pre-compaction of the reinforcement during the impregnation phase [6], but this phenomenon will be 
disregarded in the present study. Process induced stresses may lead to the development of several defects [7] which may alter the final part health, including possible shape distortions, development of microcracks or delamination.

Facing these process induced defects, it appears as crucial to master the process in order to limit the stresses and their consequences. Where a trial and error method is time and cost consuming, the precise modeling of the phenomena occurring during cooling seems a promising way to optimize the process conditions and lower the stresses levels. Such a modeling necessitates taking into account the different sources of development of residual stresses [5,6], including heat transfer, crystallization kinetics and mechanical behavior of the involved material.

Heat transfer within a TP composite part during cooling is commonly modeled thanks to the conductive heat transfer equation [8]. A source term is taken in consideration, corresponding to the crystallization enthalpy and depending on the crystallization kinetics. This latter is described thanks to several approaches, depending on the material studied, but the Avrami [9] and the Nakamura [10] models are the most found in the literature.

The thermoplastic composites mechanical behavior during cooling has been treated thanks to several approaches in the literature. Different constitutive laws were investigated, and a recent study proposed to compare them [11]. Among them, the linear thermo-elastic approach can be found in many references [12-15]. Even though it provided numerical results close to measured ones, it was pointed out that this model overestimates the stresses levels in composite parts as it does not allow for stresses relaxation. An improvement based on an incremental version of this thermo-elastic law has been proposed [16], which correctly takes into account the evolution of the material properties during cooling. According to the literature, the results provided by this improved constitutive law are more accurate, but still do not allow for stresses relaxation. To overcome this issue, the use of thermo-visco-elastic constitutive laws have been developed during the last forty years $[15,17,18]$, and showed very promising descriptions of the material behavior during cooling but required higher computational cost. 
Different methods can then be found to solve the mechanical problem, and thus estimate the distribution of residual stresses during cooling. At the plies and part scales, two main approaches can be found [6]: the Finite Element Method (FEM) $[14,15,17,19]$ or the Classical Laminate Theory (CLT) $[13,16]$. The first one allows for complex shapes study, and provides a unified frame for the solution of the coupled thermal problem together with the crystallization kinetics as well as the mechanical equilibrium. However, in the case of complex stacking sequences, a fine discretization is needed through the thickness of the part leading to longer computation times. On the opposite, the CLT is well adapted to the study of relatively thin and flat parts with large in-plane dimensions. It was however found inefficient when applied to unsymmetrical laminates, as it was unable to reproduce the experimentally observed cylindrical shapes of cross-ply laminates [20]. A modification of the CLT was proposed [20,21] to overcome this limitation, but it has never been applied in the case of a reinforced semi-crystalline thermoplastic matrix composite.

Several composite material properties and their evolution during cooling and crystallization are needed in order to feed the previous models, including thermo-physical (i.e. thermal conductivity tensor, heat capacity and specific volume), physical (crystallization kinetics, enthalpy and shrinkage tensor) and mechanical properties (mechanical stiffness and thermal expansion tensor) [8,16]. Their characterization has already been widely discussed in the literature and will not be developed here. When monitoring the development of residual stresses, numerous studies defined the Stress Free Temperature (SFT) as the temperature at which residual stresses start to develop, but are still negligible. Depending on the studied composite and more precisely the matrix, this temperature corresponds to either the peak crystallization temperature $T_{P C}$ for semi-crystalline polymers or the glass transition temperature $T_{g}$ for amorphous ones [5]. It is considered that the stresses completely relax when the temperature is higher than the SFT when using incremental linear elastic laws [12-14,16]. Below this temperature, stresses start to develop and to accumulate. The SFT was investigated mainly for polyetheretherketone (PEEK) matrix composites, and no value could be found for the PA66 matrix and the associated composite materials.

The goal of this study is to predict the process-induced stresses during the cooling of a glass fiber reinforced PA66 matrix composite. To achieve this objective, the SFT of this composite will first be 
explored experimentally. The measurement of the evolution of the curvature of several non-symmetrical composite plates during heating is proposed to meet this target. This method was chosen due to its ease of implementation [22] and because it has already been employed with success in the laboratory on a thermosetting composite [23]. To complete the identification of the SFT, Dynamic Scanning Calorimetry (DSC) tests are performed in order to determine the impact of the cooling rate on the peak crystallization temperature. Then, a thermomechanical modelling of the material behavior based on the modified CLT is developed, which takes into account heat transfer and crystallization kinetics through the thickness of the composite. As the studied parts present a thin thickness compared to their in-plane dimensions, the modified CLT proposed by Hyer [20] was considered as well suited to investigate the strains and stresses state within the laminate. The developed model is fed with thermomechanical properties already measured in a previous study [24]. The numerical curvature of the asymmetric ply sequences square plates are then estimated during the cooling, and compared with the experimentally measured ones in order to validate the developed model. The estimated residual stresses distribution through the thickness of the studied parts is discussed regarding several experimental observations. The interest of such model is discussed by confronting the results with ones considering constant thermomechanical properties and linear displacement-strain relations. Finally, the sensitivity of the model on the cooling rate and the fiber volume fraction is investigated and discussed.

\section{Materials and methods}

\subsection{Materials}

This study focuses on a composite material composed of a PA66 matrix developed at lab scale and continuous glass fiber quasi-unidirectional reinforcement. This material comes from recent developments and research concerning low-viscosity thermoplastic matrix for LCM and is part of the French TAPAS research program [2-4]. This program led to the development of a specifically modified PA66 matrix (developed by Solvay) and an adapted reinforcement to optimize the impregnation phase. As described in [24], the quasi-unidirectional reinforcement is composed of approximately $50 \% \mathrm{vol}$ of fibers. 95\% of the fibers are directed along the warp direction, and 5\% along the weft direction. The 
warp and weft fibers are woven following a plain weave pattern. The material thermomechanical characterization was completely performed in the previously mentioned study [24], where more details concerning this material can be found.

Five square plates were manufactured by thermoforming at Solvay in Saint Fons (France) on a PEI LAB 600 PA thermoforming press. The plates were manufactured according to the same protocol, which is presented in the following lines. PA66 powder layers and continuous glass fibre plies were successively stacked on the frame of the press. They were first heated from room temperature to $280^{\circ} \mathrm{C}$ and hold for 3 minutes under a compressive pressure of $0.3 \mathrm{MPa}$ in order to melt the matrix. The part was then cooled to room temperature at a rate of $20 \mathrm{~K} / \mathrm{min}$ before being released. All five square plates follow a $\left[90_{4} 0_{4}\right]$ ply sequence, and their final dimensions are $220 \times 220 \times 3.4 \mathrm{~mm}^{3}$. One of the plates was then cut into 5 strip samples of $220 \times 10 \mathrm{~mm}^{2}$ of in-plane dimensions. For the different following measurement techniques, all the samples were dried under a $-0.09 \mathrm{MPa}$ vacuum at $90^{\circ} \mathrm{C}$ during at least 10 hours prior testing to ensure the samples are dry.

\subsection{Stress Free Temperature measurement}

The five $\left[\begin{array}{ll}90_{4} & 0_{4}\end{array}\right]$ composite strips of in-plane dimensions $220 \times 10 \mathrm{~mm}^{2}$ were dedicated to the measurement of the Stress Free Temperature of the composite. After drying, each sample was placed in a Binder MKF 56 climate chamber equipped with a glass window. The temperature in the climate chamber was controlled and set to a precise temperature level ranging from 25 to $180^{\circ} \mathrm{C}$, and the humidity was set to $0 \% \mathrm{HR}$. The samples were hanged in the chamber with small steel clips in order to let them deform freely. They were positioned so as their lateral sides were visible from the windowed door (Fig. 1a). A camera was placed in front of the window and positioned in order to capture the lateral profiles of the strip samples (Fig. 1b). The isothermal level was hold for at least 10 minutes prior shooting a photograph to achieve thermal equilibrium of the samples. The obtained picture was then treated thanks to the Image $\mathrm{Image}$ analysis software. On each sample profile, three points $P_{1}, P_{2}$ and $P_{3}$ were extracted on the left edge of the sample side (Fig. 1b). The points $P_{1}$ and $P_{3}$ are chosen on the opposite extremities of the strip, while the point $P_{2}$ is chosen approximately at the middle of the strip. The coordinates $\left(X_{i}, Y_{i}\right)$ of each point is obtained in pixels in ImageJ. The pixels coordinates are 
converted to meters thanks to a ruler placed in the climatic chamber (Fig. 1a), which length is pictured at room temperature. The objective is then to determine the radius $R$ of the circle passing through the three points $P_{1}, P_{2}$ and $P_{3}$. It consists in finding the point $P_{0}$ of coordinates $\left(X_{0}, Y_{0}\right)$, which leads to the equality between the distances $P_{0} P_{1}, P_{0} P_{2}$ and $P_{0} P_{3}$ (Fig. 1c). It leads to the resolution of the system of two equations (Eq. 1), where the two unknowns to be determined are $X_{0}$ and $Y_{0}$. Once identified, the radius $R$ is simply the distance between $P_{0}$ and any of the points $P_{i}$. The problem (Eq. 1 ) was solved with the software Matlab 2017a.

a)

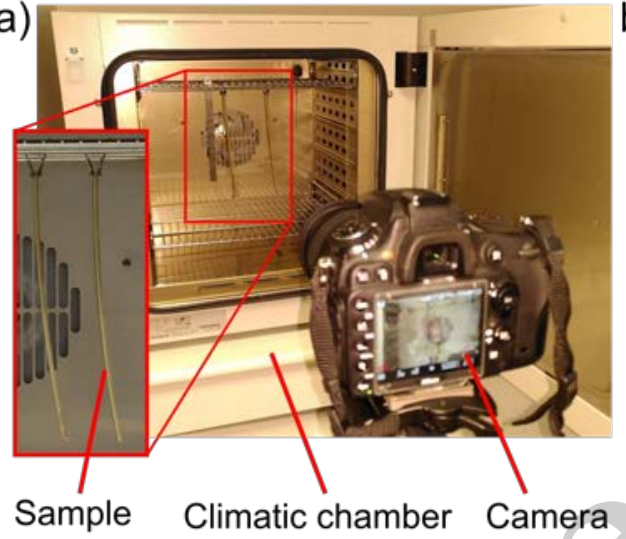

b)

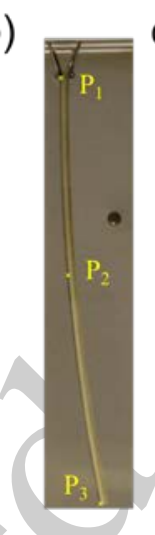

c)

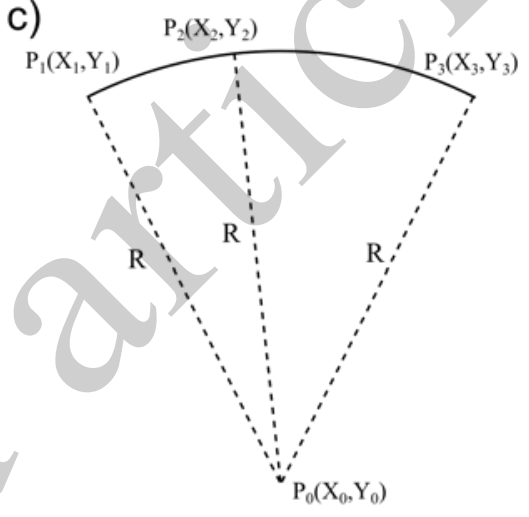

Figure. 1: SFT measurement a) Experimental set up b) image analysis c) geometrical representation.

$$
\left\{\begin{array}{l}
\left(X_{1}-X_{0}\right)^{2}+\left(Y_{1}-Y_{0}\right)^{2}=\left(X_{2}-X_{0}\right)^{2}+\left(Y_{2}-Y_{0}\right)^{2} \\
\left(X_{1}-X_{0}\right)^{2}+\left(Y_{1}-Y_{0}\right)^{2}=\left(X_{3}-X_{0}\right)^{2}+\left(Y_{3}-Y_{0}\right)^{2}
\end{array}\right.
$$

The curvature of the sample was then easily calculated as the inverse of its radius $R$. By monitoring the evolution of the curvature with the temperature, it was possible to determine the apparent SFT as the temperature at which the curvature vanishes. The whole protocol was already described in previous studies, either on thermoset $[23,25]$ or thermoplastic $[12,13]$ composites.

\subsection{Curvature measurement}

An experimental method was developed in order to follow the evolution of the curvature of the four asymmetric laminate square plates. A speckle pattern was painted on the top of these plates. They were then hanged in the same climatic chamber as previously described with thin iron wires, and their out- 
of-plane shape was monitored during heating over the same temperature range. A VIC-3D image correlation system from Correlated Solutions was used to measure the top surface of the plate (Fig. 2a).
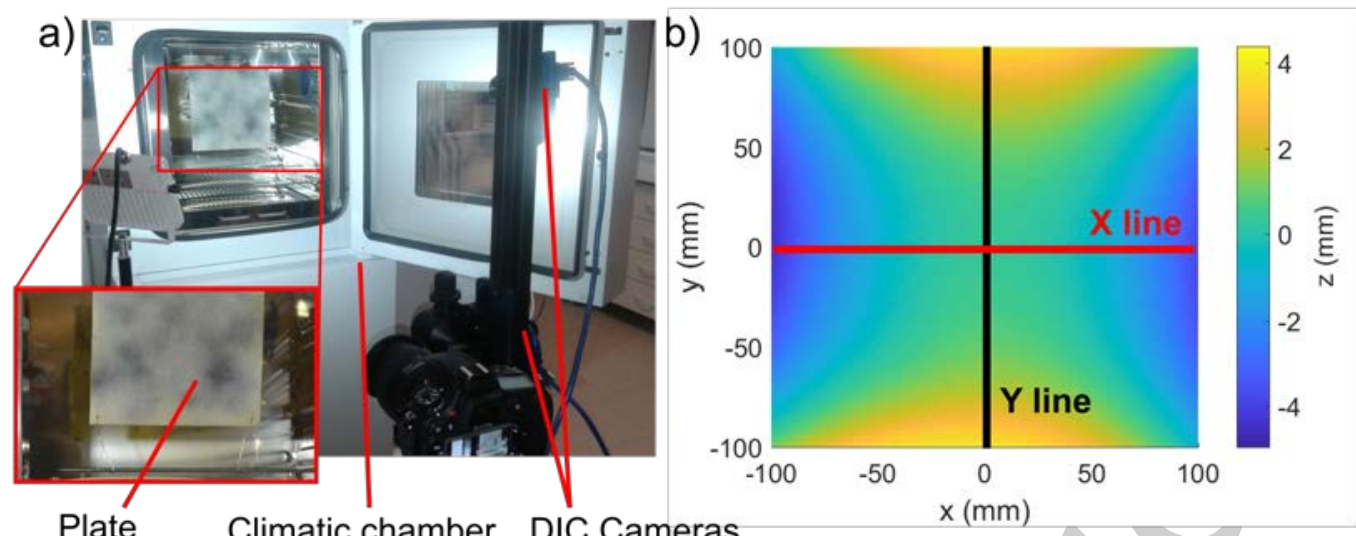

Plate Climatic chamber DIC Cameras

Figure. 2: Curvature measurement a) Experimental set up and b) Analysis of the surface deflection of the plate.

Regarding the studied ply sequence, the plate shape is expected to be either cylindrical or saddle-like, along its principal directions $x$ and $y$ [26]. The analysis of the surfaces obtained from the digital image correlation can therefore be reduced to the study of the main curvatures along the principal axis, denoted as $a$ and $b$ along the $x$ and $y$ directions, respectively. They were obtained by extracting the surface deflection in the $x$ and $y$ directions along the lines $X$ and $Y$ represented in Fig. 2b. For both directions, the point cloud corresponding to the extracted lines was interpolated thanks to a quadratic function in Matlab 2017a software, thus directly leading to the curvatures $a$ and $b$.

The presence of the windowed door slightly modifies the optical paths. This is caused by the refraction due to the difference in optical index between the glass and the ambient air. The measured curvatures have therefore to be corrected. The correction factor was obtained by measuring the curvatures at room temperature first without the window and then with the window. The results from both measurements are gathered in Table 1.

The correction coefficients are easily obtained by dividing the curvature without window by the one with the window. This leads to the corrections $C_{a}=1.037$ and $C_{b}=0.968$, which will be assumed as 
constant over the whole temperature range. The corrected curvatures are then obtained by multiplying the measured curvature by the correction coefficient. This represents a rough correction and will need specific insight to improve its accuracy. This is however not the goal of this article.

Table 1: Measured curvatures at room temperature.

\begin{tabular}{cccc} 
Curvature & Unit & Without window & With window \\
\hline$a$ & $\left(\mathrm{~m}^{-1}\right)$ & $-0.894 \pm 0.023$ & $-0.862 \pm 0.025$ \\
$b$ & $\left(\mathrm{~m}^{-1}\right)$ & $0.677 \pm 0.040$ & $0.699 \pm 0.037$
\end{tabular}

\subsection{DSC measurements}

To complete the identification of the SFT, the crystallization of the PA66 matrix is investigated for several cooling rates thanks to a Mettler Toledo DSC device. Samples of approximately $10 \mathrm{mg}$ were sealed in DSC crucibles and each one was submitted to an initial temperature rise from room temperature to $290^{\circ} \mathrm{C}$ at $2 \mathrm{~K} \cdot \mathrm{min}^{-1}$ followed by a 10 minutes temperature hold at $290^{\circ} \mathrm{C}$ in order to melt and erase the thermal history of the matrix. Then, the samples were cooled from $290^{\circ} \mathrm{C}$ to $25^{\circ} \mathrm{C}$ at cooling rates of -2 , $-10,-25$ and $-50 \mathrm{~K} \cdot \mathrm{min}^{-1}$. The crystallization enthalpy was measured according to the standard method, which consists in calculating the time integral of the released heat flux during crystallization. The peak crystallization temperature $T_{P C}$ is also identified. It corresponds to the temperature where the maximum of the monitored heat flux is recorded.

\subsection{Thermomechanical properties identification}

The comprehension of the mechanical behavior of the material under a wide range of temperature is mandatory to understand and predict the development of residual stresses during its processing. The identification of the material thermomechanical behavior was thoroughly described in a previous study [24] and is quickly reminded here.

Two approaches were employed. The first one aimed at characterizing the PA66 matrix thanks to a volumetric dilatometer and to a Dynamic Mechanical Analyser (DMA). This led to the identification of the volumetric coefficient of thermal expansion, of crystallization shrinkage, to the bulk modulus and 
to the elastic modulus of the matrix over a wide temperature range (from 25 to $250^{\circ} \mathrm{C}$ ). Considering the properties of the glass fibres as known and thanks to analytical homogenization methods, it was possible to estimate the thermomechanical properties of the composite material, i.e. the in-plane elastic moduli $E_{11}$ and $E_{22}$, shear modulus $G_{12}$ and Poisson's coefficient $v_{12}$, the coefficients of thermal expansion $\alpha_{11}$ and $\alpha_{22}$ and of crystallization shrinkage $\beta_{11}$ and $\beta_{22}$. The subscripts ' 1 ' and '2' refer to the longitudinal and transversal direction relative to the fibres in the involved material, respectively. The second approach resided in the direct characterization of these properties on the composite material. The DMA tests permitted to determine the evolution of the in-plane elastic moduli $E_{11}$ and $E_{22}$ with the temperature, while a linear dilatometer led to the identification of the transverse coefficient of thermal expansion $\alpha_{22}$. The measured values were compared with the estimated ones, leading to a good agreement. This permitted to validate the whole characterization approach and to consider that the properties obtained through the homogenization method were representative of the material real properties.

a)

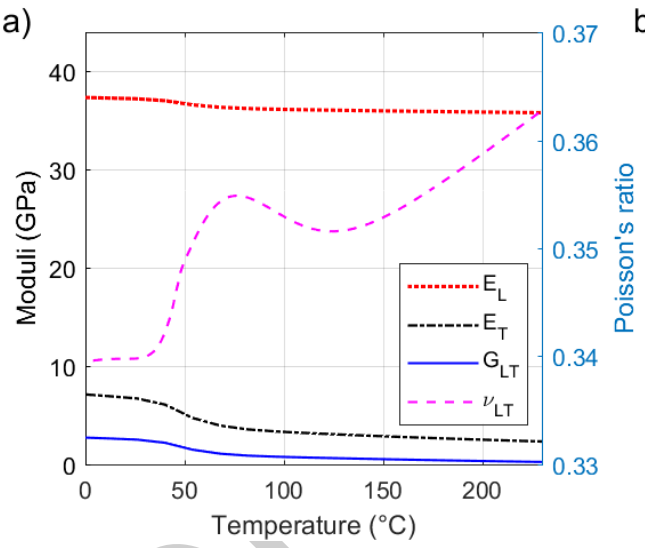

b)

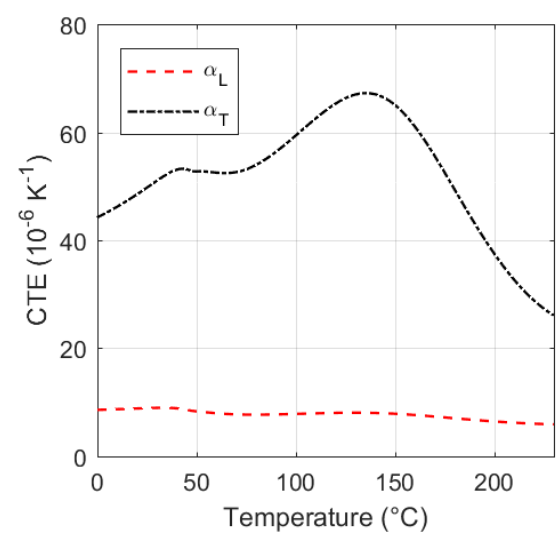

Figure. 3: Thermomechanical properties of the composite material estimated in [22] with 50\% of fibers in volume a) In-plane moduli and Poisson’s ratio b) In-plane coefficient of thermal expansion.

The obtained properties and their evolution with the temperature are represented in Fig. 3 a and b, except for the crystallization shrinkage which values were found nearly constant as a function of the temperature, leading to $\beta_{11}=-0.002 \%$ and $\beta_{22}=-1.04 \%$. More details and discussions on the characterization method and the obtained properties can be found in [24]. 


\section{Experimental characterization}

\subsection{Stress free temperature}

The evolution of the strips curvature measured to determine the SFT is represented in Fig. 4. The curvature decreases with temperature from 25 to $180^{\circ} \mathrm{C}$. The curvature measured at $25^{\circ} \mathrm{C}$ is $1.05 \mathrm{~m}^{-1}$ while the one obtained at $180^{\circ} \mathrm{C}$ reaches $0.12 \mathrm{~m}^{-1}$. This value is nearly 9 times lower than the one measured at room temperature. A linear extrapolation function is proposed (Eq. 2), which minimizes the difference with the experimental data according to the least-squares method.

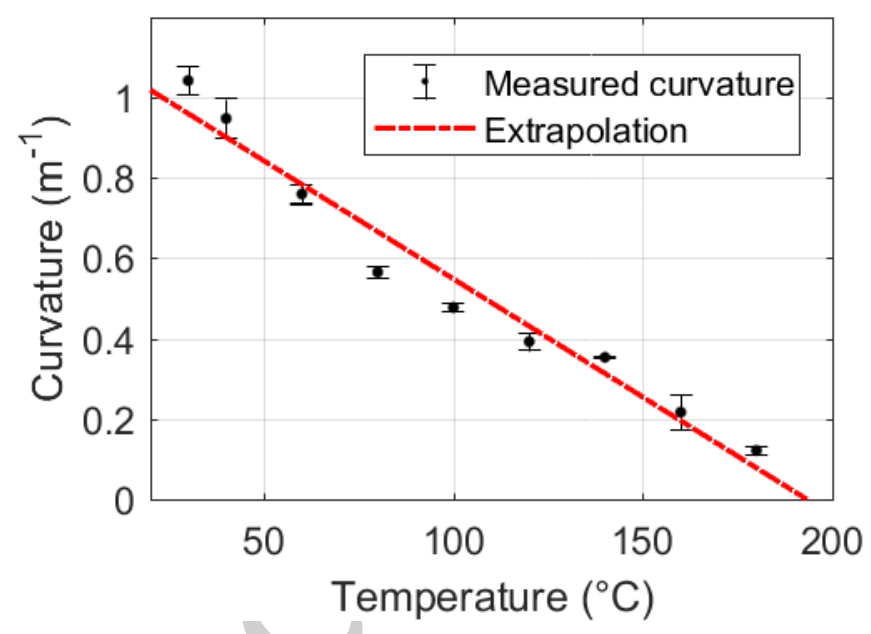

Figure. 4: Evolution of the curvature of [90_4 0_4] composite strips to determine the SFT.

$$
f(T)=-0.0059 T+1.1367
$$

This equation nullifies at a temperature of $193^{\circ} \mathrm{C}$, which will be considered as the Apparent Stress Free Temperature (ASFT) of the studied material: $T_{A S F}=193^{\circ} \mathrm{C}$.

\subsection{Curvature}

The evolution of the main curvatures of the $\left[90_{4} 0_{4}\right]$ plates measured thanks to Digital Image Correlation is represented in Fig. 5. These different results are already corrected according to the correction coefficients $C_{a}$ and $C_{b}$. The standard deviation is lower than $0.04 \mathrm{~m}^{-1}$, thus showing an excellent reproducibility of the experiment over the different tested samples. For both directions, the curvature 
evolves linearly with the temperature over the whole temperature range. Both data were extrapolated according to linear regressions, which are also plotted in Fig. 5. From the extrapolations, it appears that the ASFT for the composite plates is also close to $193^{\circ} \mathrm{C}$, as both extrapolated lines equal zero at $190^{\circ} \mathrm{C}$.

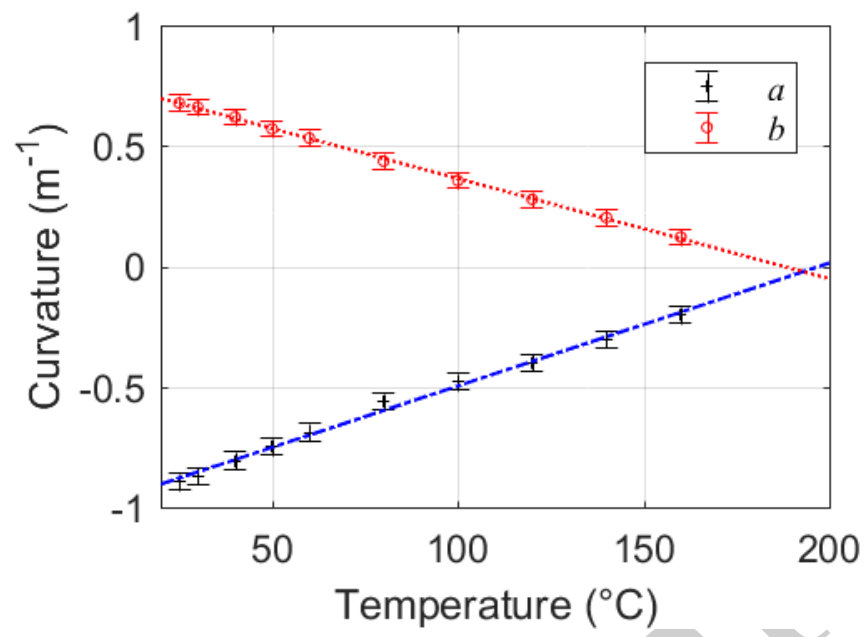

Figure. 5: Evolution of the curvature of the [90_4 0_4] composite plates. The markers represent the experimental data and the continuous lines the linear extrapolations.

As $a$ is negative and $b$ is positive, this corresponds to a saddle like shape, as observed in Fig. 2b. It seems that the amplitude of the curvature $a$ is always superior to the curvature $b$ by a multiplication factor close to 1.21. Therefore, the saddle shape is not perfectly equilibrated. This can be explained by possible fiber volume fraction variations through the thickness of the laminate due to the compression phase [6], by non-symmetric cooling, by fibre misalignement or by the micro-structure of the elementary ply [24]. These hypothesises will however not be discussed here.

It has to be noted that the curvature of the strips obtained in the previous section 3.1 is higher than the one obtained on the plate they come from. Indeed, at $30^{\circ} \mathrm{C}$, the strips curvature reaches $1.04 \mathrm{~m}^{-1}$ while the plates curvature along the $\mathrm{x}$ and $\mathrm{y}$ axis were of $-0.89 \mathrm{~m}^{-1}$ and $0.68 \mathrm{~m}^{-1}$, respectively. This increase is due to the redistribution of the stresses in the strip after cutting and to a modification of its bending stiffness, which lead to a modification of its curvature. This phenomenon has been used to characterize the residual stresses in thick composite laminates [27] and in thin composite plates [28] but will not be further discussed here. 


\subsection{DSC results}

The heat flux obtained in DSC during the crystallisation of the matrix under a $2 \mathrm{~K} / \mathrm{min}$ cooling rate is represented in Fig. 6a. During the early moments of cooling (from 290 to $235^{\circ} \mathrm{C}$ ), the flux remains constant and close to a value of $0.010 \mathrm{~W} / \mathrm{g}$. It then quickly rises to its maximum value of $0.483 \mathrm{~W} / \mathrm{g}$ at a temperature of $229.6^{\circ} \mathrm{C}$. It decreases rapidly until reaching a value of $0.06 \mathrm{~W} / \mathrm{g}$ at $225^{\circ} \mathrm{C}$, before decreasing more slowly with the temperature. From these observations and based on the work of Faraj [3], it appears the crystallization happens between $235^{\circ} \mathrm{C}$ and $215^{\circ} \mathrm{C}$ for this cooling rate.
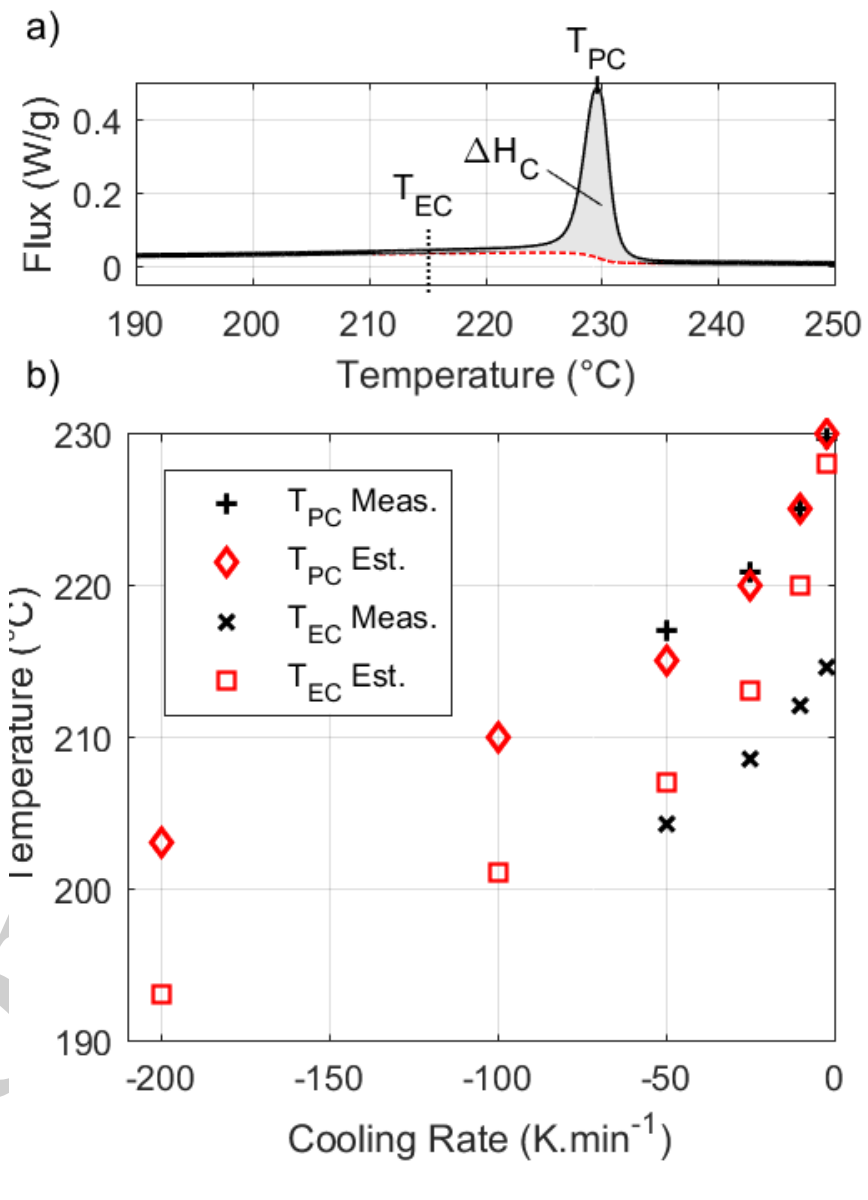

Figure 6: DSC results a) Heat flux obtained during crystallization under a cooling rate of $-2 \mathrm{~K} \cdot \mathrm{min}^{-1} \mathrm{~b}$ )

Evolution of the measured and estimated peak crystallization temperature $T_{P C}$ and end of crystallization temperature $T_{E C}$.

From this heat flux evolution, it is possible to identify the Peak Crystallization Temperature $T_{P C}$ as the temperature at which the heat flux reaches its maximum value. The area beneath the curve heat flux 
curve during corresponding directly gives the crystallization enthalpy per unit mass $\Delta \mathrm{H}_{\mathrm{C}}$. It corresponds to the integral of the heat flux from the temperature at which crystallization started (i.e. $235^{\circ} \mathrm{C}$ for a cooling rate of $2 \mathrm{~K} / \mathrm{min}$ ) to the end of crystallization temperature $T_{E C}$ (i.e. $215^{\circ} \mathrm{C}$ for a cooling rate of $2 \mathrm{~K} / \mathrm{min})$.

Considering all the cooling rates, the mean crystallization enthalpy $\Delta H_{C}$ value reached $40.2 \pm 1.3 \mathrm{~J}^{-g^{-1}}$. This corresponds to $20 \%$ of crystallinity as the theoretical enthalpy of the PA66 crystal reaches $195 \mathrm{J.g}$ ${ }^{1}$ [3]. As a consequence, it appears the cooling rate does not affect the crystallinity fraction, both on the

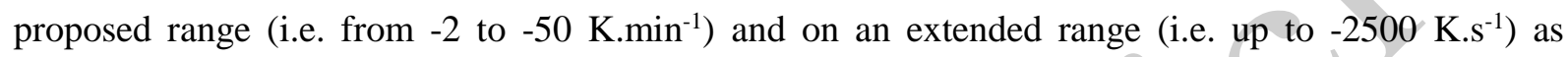
demonstrated by Faraj et al. [4]. It will therefore be considered that the cooling rate does not affect the development of the material mechanical properties, and these ones will only depend on the temperature once crystallization is complete.

The evolutions of the experimentally determined $T_{P C}$ and $T_{E C}$ with the cooling rate are represented in Fig. 6b. Low cooling rates (e.g. $-2 \mathrm{~K} \cdot \mathrm{min}^{-1}$ ) lead to a $T_{P C}$ close to $230^{\circ} \mathrm{C}$ and a $T_{E C}$ close to $215^{\circ} \mathrm{C}$. For increasing cooling rates, $T_{P C}$ and $T_{E C}$ decrease reaching $217^{\circ} \mathrm{C}$ and $204^{\circ} \mathrm{C}$ at $-50 \mathrm{~K} \cdot \mathrm{min}^{-1}$, respectively.

\section{Residual stresses prediction}

The prediction of the residual stresses during the cooling of the studied TP composite requires the development of a multiphysical model, which accounts for heat transfer, crystallization kinetics and the mechanical behaviour of the involved materials. This would then permit to predict the evolution of the curvature measured in the previous section, as well as the associated stresses states. The proposed model is based on the modified lamination theory as described by Hyer [20], which is adapted to the study of semi-crystalline TP composites for the first time. The assessment of heat transfer and crystallization kinetics is firstly described, followed by the thermomechanical modelling. 


\subsection{Heat transfer and crystallization kinetics}

In the numerous studies based on the modified laminate theory proposed by Hyer [29-32], the temperature is considered as uniform through the thickness of the laminate. This can be assumed when studying thin thermoset composites used in the aeronautical industry, as the proposed temperature cycles are usually based on slow cooling (around $5^{\circ} \mathrm{C} / \mathrm{min}$ ), thus ensuring a relative temperature homogeneity through the thickness of the part. However, when studying the forming of thermoplastic plates, higher cooling rates are faced, up to $300^{\circ} \mathrm{C} / \mathrm{min}$ on the laminate surface. This may lead to high temperature and crystallization gradients when forming thick parts [8], which needs to be investigated in the case of thin parts such as the plates manufactured in this study. A heat transfer model is therefore considered to take into account these gradients. Due to the relatively thin characteristic of the plates compared to their inplane dimensions, heat transfer is considered as $1 \mathrm{D}$ through the thickness of the laminate. It can as a consequence be described thanks to the 1D conductive heat transfer equation (Eq.(3)). This latter is coupled with the crystallization kinetics identified by Faraj et al. [4] for the studied composite, and given by (Eq. (4)\&(5)).

$$
\begin{gathered}
\rho C_{p} \frac{\partial T}{\partial t}=\frac{\partial}{\partial z}\left(K_{z z} \frac{\partial T}{\partial z}\right)+\left(1-V_{f}\right) \rho_{m} \Delta H_{m} \frac{\partial C}{\partial t} \\
\frac{\partial C}{\partial t}=n \cdot K_{N a k}(T) \cdot[1-C(t)]\left[\ln \left(\frac{1}{1-C(t)}\right)\right]^{\frac{n-1}{n}}, \\
K_{N a k}(T)=\left(K_{A v}(T)\right)^{\frac{1}{n}}
\end{gathered}
$$

where $\rho, C_{p}, K_{z z}$ are the composite material density, heat capacity and through-thickness thermal conductivity, respectively, $V_{f}$ is the fiber volume fraction, $\rho_{m}, \Delta H_{m}$ are the matrix density and crystallization enthalpy respectively. All of these properties have been identified by Faraj in his PhD thesis [3] and will not be discussed here. They are gathered in Table 2. Finally, $n$ is the Avrami exponent, $K_{N a k}$ is the Nakamura kinetic function which is linked with the Avrami kinetic function $K_{A v}$ via the relation (5). The different crystallization kinetics parameters (i.e. $n, K_{N a k}$ and $K_{A v}$ ) have already been experimentally identified by Faraj et al. [4]. This led to an Avrami coefficient $n=3$ and to kinetic 
function values presented in Fig. 7. The peak crystallization temperature $T_{P C}$ was numerically estimated from the crystallization kinetics for cooling rates from $-2 \mathrm{~K} / \mathrm{min}$ to $-200 \mathrm{~K} / \mathrm{min}$. The obtained $T_{P C}$ values are plotted in Fig. $6 \mathrm{~b}$ with the experimentally measured ones. The estimated $T_{P C}$ are less than $2^{\circ} \mathrm{C}$ far from the experimentally measured ones, therefore permitting to validate the crystallization model proposed by Faraj [3].

Table 2: Thermo-physical properties [3-4].

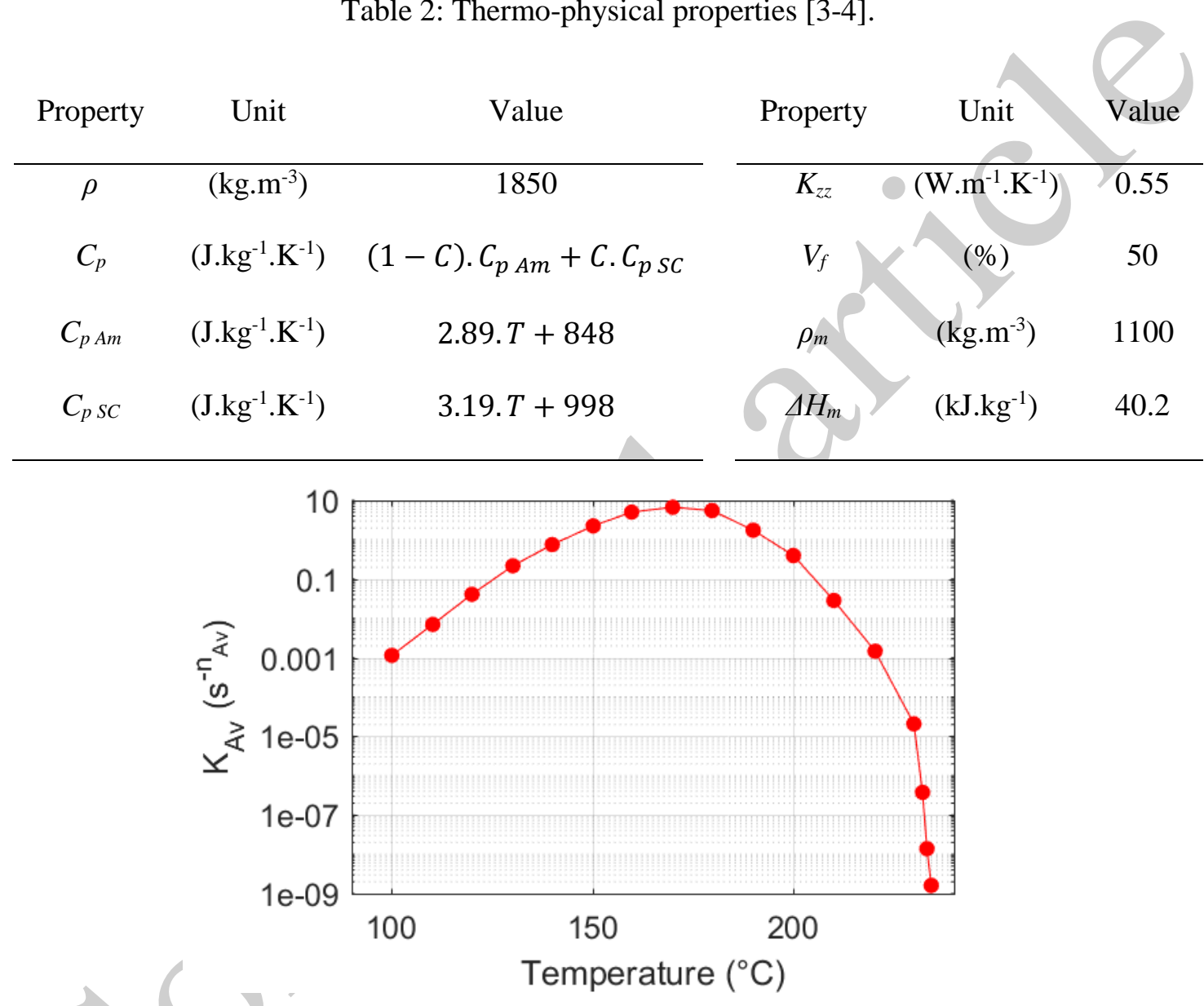

Figure. 7: Evolution of the Avrami kinetic function identified by Faraj et al. [4].

During the manufacturing of the plates under a $20 \mathrm{~K} / \mathrm{min}$ cooling rate, the surface temperatures recorded on the top and the bottom of the plates were monitored with a maximum uncertainty of $1.77^{\circ} \mathrm{C}$ compared to the imposed temperature cycle. The thermal contact resistance between the mold and the part is considered as negligible. As a consequence, the upper and lower surfaces of the laminate are submitted to the same imposed temperature corresponding to the desired temperature cycle $T_{\text {imp }}$. The boundary conditions of the previous system of equations is given by: 


$$
\begin{gathered}
T(t=0, z)=T_{i n i} \\
T(t, z=e / 2)=T(t, z=-e / 2)=T_{i m p} \\
C(t=0, z)=0
\end{gathered}
$$

The whole thermal problem coupled with the crystallization kinetics (Eqs. (3)-(8)) is then resolved thanks to a finite different scheme using Matlab 2017a software. The laminate thickness is discretized thanks to $N_{D}$ nodes at which $T$ and $C$ are calculated for each time step. A convergence analysis led to $N_{D}=100$ nodes. This leads to the temperature and crystallization distribution through the thickness of the laminate. The mean values of the temperature and crystallization over each plies are then computed, following the method described in [33], and will feed the thermomechanical model described in the following section.

\subsection{Thermomechanical behaviour modelling}

The composite plates presented in section 2 exhibit large in-plane dimensions compared to their thickness. The studied ply sequence is asymmetrical, thus leading to curvatures as pointed out in section 3. Considering these two points, the laminate theory appears as a good candidate to translate the material behaviour during cooling. Hyer modified the classical laminate theory (CLT) [20] so as to reproduce the behaviour of unsymmetric cross-ply composite laminates submitted to temperature variations. His theory relies on the assumption of the displacement field in order to reproduce the experimentally observed shapes of the aforementioned composite laminates. Usually, the out-of-plane displacement $w$ is chosen to be

$$
w(x, y)=\frac{1}{2}\left(a x^{2}+b y^{2}\right)
$$

where $a$ and $b$ are the curvatures along the $x$ and $y$ directions, respectively, as described in section 2.3. Using several geometrical assumptions given in [21], the approximate in-plane displacement fields $u^{0}$ and $v^{0}$ are given by 


$$
\begin{aligned}
& u^{0}(x, y)=c x-\frac{a^{2} x^{3}}{6}-\frac{a b x y^{2}}{4} \\
& v^{0}(x, y)=d y-\frac{b^{2} y^{3}}{6}-\frac{a b x^{2} y}{4}
\end{aligned}
$$

where $c$ and $d$ are constants to be determined. As the out-of-plane displacements are considered to be many times higher than the laminate thickness, the in-plane strains can be calculated thanks to the von Karman approximation of the Green's strain measure:

$$
\begin{gathered}
\varepsilon_{x x}=\frac{\partial u^{0}}{\partial x}+\frac{1}{2}\left(\frac{\partial w}{\partial x}\right)^{2}-z \frac{\partial^{2} w}{\partial x^{2}} \\
\varepsilon_{y y}=\frac{\partial v^{0}}{\partial y}+\frac{1}{2}\left(\frac{\partial w}{\partial y}\right)^{2}-z \frac{\partial^{2} w}{\partial y^{2}} \\
\varepsilon_{x y}=\frac{1}{2}\left(\frac{\partial u^{0}}{\partial y}+\frac{\partial v^{0}}{\partial x}+\left(\frac{\partial w}{\partial x}\right)\left(\frac{\partial w}{\partial y}\right)\right)-z \frac{\partial^{2} w}{\partial x \partial y},
\end{gathered}
$$

The total potential energy of the laminate can then be expressed as the sum of the potential energy of each $n$ ply in Eq. (15), assuming a plane-stress formulation of the constitutive law Eq. (16) expressed in the global coordinate system of the laminate $(x y z)$ :

$$
\begin{gathered}
W=\sum_{n=1}^{m} \frac{1}{2} \int_{V} \sigma_{i j}^{n} \varepsilon_{i j} d V, \\
\sigma_{i j}^{n}=C_{i j k l}^{n}\left(\varepsilon_{k l}-\alpha_{k l}^{n} \Delta T^{n}\right),
\end{gathered}
$$

where the $\sigma_{i j}$, $C_{i j k l}$ and $\alpha_{k l}$ are the components of the stress, reduced mechanical stiffness and thermal expansion tensors, respectively, and $\Delta T$ is the temperature variation from the initial temperature. The superscript $n$ refers to the $n$-th ply of the laminate. $V$ corresponds to the volume of the $n$-th ply, which is delimited by its length, width and minimum and maximum thickness. The reduced stiffness matrix is calculated based on the in-plane mechanical properties of the composite [34], i.e. the longitudinal and transversal Young's moduli $E_{L}$ and $E_{T}$, the shear modulus $G_{L T}$ and the Poisson's ratio $v_{L T}$. 
The determination of the minimum for the total potential energy $W$ consists in finding the values of $a$, $b, c$ and $d$ so that the first variation of $W$ is zero. The minimization of $W$ can lead to different solutions (up to three), corresponding to different equilibrium shapes. The solution process is thus completed by a stability criterion, consisting in the second derivative of $W$. If it is positive definite, then the solution is stable. The whole resolution procedure is performed within the Symbolic Math toolbox in Matlab $R 2017 a$ software. For more details on the resolution and the stability criterion, the reader may refer to [20]. Once the different values of $a, b, c$ and $d$ are determined for a given temperature step $\Delta T$, it is possible to evaluate the residual stress through the thickness of the laminate thanks to Eqs. (9) to (16).

The model developed by Hyer is however limited to the study of cross-ply laminates submitted to thermal expansion phenomena with constant mechanical properties during the whole cooling process with a uniform temperature through the thickness of the laminate. Several enhancements are therefore necessary to model correctly the material behaviour and are proposed in the following.

The constitutive law used to describe the material behaviour often consists in a linear thermo-elastic law (Eq. (16)) with constant properties (i.e. thermal expansion coefficients and elastic moduli). As shown in [24] and plotted in Fig. 7 for the studied composite material, these properties highly depend on the temperature and non-negligible variations occur along the whole temperature range during cooling. Furthermore, semi-crystalline thermoplastic composites are submitted to crystallization shrinkage, which has to be considered in the constitutive law. To correctly take into account these phenomena, an incremental constitutive law [16] is considered (Eq.(17)), which takes into account the evolution of the material stiffness during cooling, as well as its thermal expansion and crystallization shrinkage.

$$
\Delta \sigma_{i j}=C_{i j k l}\left(\Delta \varepsilon_{k l}-\alpha_{k l} \Delta T-\beta_{k l} \Delta C\right)
$$

where $\Delta \sigma_{i j}$ and $\Delta \varepsilon_{i j}$ are the increments of the stress and strain tensors components over one time step, respectively, $\Delta T$ and $\Delta C$ are the increments of temperature and crystallinity over one time step, respectively, and $C_{i j k l}, \alpha_{k l}$ and $\beta_{k l}$ are the instantaneous components of the reduced stiffness, thermal expansion and crystallization shrinkage tensors, respectively. For each ply, the values of $\Delta T$ and $\Delta C$ are computed according to the mean values obtained over each ply as described in section 5.1. This allows 
taking into account the temperature and crystallization gradients through the thickness of the laminate. It has to be noted that, in Eq. 17, the stress increment depends not only on the evolution of the mechanical stiffness, but also on the evolution of the strain increment, and more precisely on the product between those two quantities through the term $C_{i j k l} \alpha_{k l} \Delta \mathrm{T}$.

To complete this mechanical modelling of the composite behaviour during cooling, the stresses are considered to accumulate once the ply temperature is lower than the stress free temperature (SFT). This temperature is chosen to be the peak crystallization temperature $T_{P C}$ as proposed in the literature for semi-crystalline polymer composites [5]. This temperature was identified experimentally in section 3.3 and numerically in section 4.1 for the different cooling rates. This phenomenon is taken into account by considering negligible values of the material stiffness components $C_{i j k l}$ when $T>$ SFT. The negligible value was set to 0 for the in-plane transversal Young's modulus $E_{T}$ and the in-plane shear modulus $G_{L T}$. The in-plane longitudinal Young's modulus $E_{L}$ highly depends on the stiffness of the fibres and is therefore considered as less dependent on the temperature as can be seen in Fig. 3a. Its value is therefore considered as not impacted by the SFT [16].

Finally, during cooling, the composite laminate is compressed by the thermoforming press and remains flat until it is released from the press. Its out-of-plane displacement $w$ is therefore considered as nil during this phase. After cooling and once the estimated temperature is $20^{\circ} \mathrm{C}$ and homogeneous through the thickness of the laminate, the laminate out-of-plane displacement $w$ is set by (9) in order to release the residual curvature. Then, the temperature is raised homogeneously up to $200^{\circ} \mathrm{C}$ by considering the temperature in each ply as identical. This is performed in order to reproduce the experiments presented in section 2.3.

\section{Numerical results and discussions}

\subsection{Validation of the heat transfer and crystallization model}

The proposed heat transfer and crystallization model exposed in section 5.1 is confronted to experimental results obtained by Faraj [3]. A composite plate of dimensions $70 \times 70 \times 5 \mathrm{~mm}^{3}$ was 
manufactured in a thermoregulated compression mould. The mould was heated up to $290^{\circ} \mathrm{C}$ and then cooled to room temperature thanks to a watercooled regulation system. This led to a cooling rate up to $250 \mathrm{~K} / \mathrm{min}$ and $130 \mathrm{~K} / \mathrm{min}$ at the surface and the core of the samples, respectively. Three thermocouples are placed in the sample: one on each face and one in the centre of the plate. The two first thermocouples record the surface temperatures $T_{1}$ and $T_{2}$ imposed on the composite plate, which therefore corresponds to the imposed condition of the model $T_{\text {imp }}$. The last thermocouple which records the core temperature $T_{\text {Core }}$ of the plate will serve as comparison point between the experimental and numerical results. The evolution of the imposed temperature, the measured and the estimated core temperature are represented in Fig. 8, together with the difference between the measured and estimated core temperature.

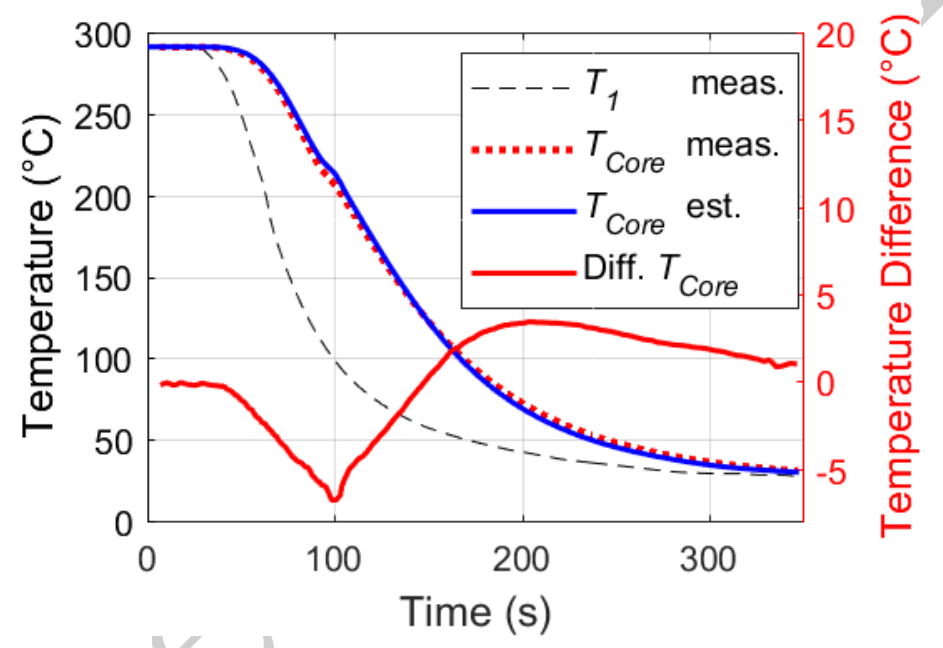

Figure. 8: Measured surface temperature T_1, measured and estimated core temperature T_Core during the cooling of the composite plate. As a reminder, the maximum recorded cooling rates are of $250 \mathrm{~K} / \mathrm{min}$ and $130 \mathrm{~K} / \mathrm{min}$ at the surface and the core of the sample, respectively.

An excellent agreement is found between the measured and estimated core temperature. They both decrease with a delay compared to the surface temperature $T_{1}$, which is due to the diffusivity of the material. From $t=95 \mathrm{~s}$ to $t=105 \mathrm{~s}$, the decrease is slightly slowed due to the crystallization of the matrix as it is an exothermal phenomenon. A maximum difference of $6^{\circ} \mathrm{C}$ is found during crystallization, which might be due to the crystallization model developed by Faraj et al. [4]. The temperature decrease is then slowed as it approaches $30^{\circ} \mathrm{C}$, leading to a core temperature difference lower than $3.5^{\circ} \mathrm{C}$. This agreement 
between the experimentally measured and the predicted core temperature permits to validate the developed thermal and crystallization model.

\subsection{Validation of the thermomechanical model}

The complete thermomechanical model is then exploited so as to reproduce the cooling phase during forming as well as the curvature measurement experiment exposed in section 4 on the $\left[90_{4} 0_{4}\right]$ composite plate. The laminate dimensions are set to $220 \times 220 \times 3.4 \mathrm{~mm}^{3}$. As a reminder, the material thermomechanical properties used to feed the model have been obtained in [24] and are summarized in section 2.5. The part is cooled from $290^{\circ} \mathrm{C}$ to $20^{\circ} \mathrm{C}$ and the cooling rate is set to $20 \mathrm{~K} / \mathrm{min}$ so as to reproduce the temperature conditions during the manufacturing of the plates performed by Solvay. This leads to low temperature gradients: the difference between the core and the surface temperature does not exceed $5.4^{\circ} \mathrm{C}$ during crystallization and $3.0^{\circ} \mathrm{C}$ after the crystallization. The evolution of the predicted curvature of the plate during cooling, demoulding and reheating is plotted in Fig. 9, together with the measured curvatures presented in section 4 .

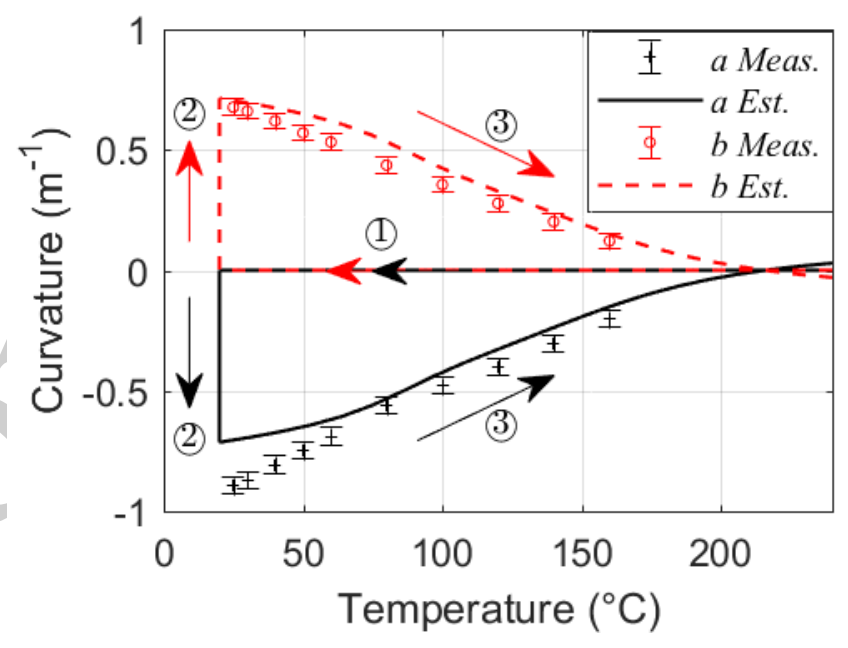

Figure. 9: Evolution of the [90_4 0_4] composite plate estimated and measured curvature with temperature. The arrows represent the cooling (1), the demoulding (2) and the reheating (3).

During the cooling phase of the forming process, the predicted curvatures $a$ and $b$ are nil from 290 to $20^{\circ} \mathrm{C}$ due to the compaction of the press. When the part is released from the mould at $20^{\circ} \mathrm{C}$, the estimated curvatures rise due to the presence of residual stresses. This leads to opposite values for the curvature 
but with the same intensity of $0.714 \mathrm{~m}^{-1}$ at room temperature. The absolute values of $a$ and $b$ are identical on the whole temperature range, but they have opposite signs. Therefore, the composite plate is assumed to follow a saddle-like shape as $a=-b$. The part shape estimated at $20^{\circ} \mathrm{C}$ is represented in Fig. 10a, emphasizing the saddle shape of the laminate. During the reheating, the estimated curvatures intensity decreases non-linearly with the temperature. The curvatures tend to 0 for a temperature close to $216^{\circ} \mathrm{C}$, which is considered as the estimated Apparent Stress Free Temperature ASFT.

The non-linear evolution of the estimated curvature was not observed by Barnes and Byerly in the case of a carbon fibre reinforced PEEK asymmetric composite [12], even though the thermo-mechanical properties used to feed their model evolved non-linearly with the temperature. In this study, the obtained non-linear evolution of the estimated curvature is explained by the non-linear evolution of the thermomechanical properties of the material (Fig. 3), and to the slight difficulties met in the identification of the transversal coefficient of thermal expansion in [24].

The estimated curvature $a$ differs from the measured one when the temperature is lower than $80^{\circ} \mathrm{C}$. The difference can be explained by the potential presence of defects in the manufactured part, which are not accounted for in the model (e.g. plies or fibre misalignment, heterogeneous fibre volume fraction...) $[6,35]$. Except from this difference, the estimated values are found in good agreement with the measured curvatures as difference between both values never exceeds $0.1 \mathrm{~m}^{-1}$. This proves the ability of the developed model to predict the strain state of the laminate after forming.

\subsection{Predicted stress state}

Together with the strain state of the laminate, the model also provides its in-plane stress state. The distribution of the in-plane stress components $\sigma_{x x}$ and $\sigma_{y y}$ are represented at $20^{\circ} \mathrm{C}$ in Fig. $10 \mathrm{~b}$ and c when the part is still in the moulding press and in Fig. $10 \mathrm{~d}$ and e when it is released. These stresses are plotted versus the position along the thickness of the laminate $z$ for several locations in the $x y$ plane. These locations are referenced as $O, W, N$ and $N W$ and are represented in Fig. 10a. The $90^{\circ}$ and the $0^{\circ}$ plies are respectively delimited between -1.7 and $0 \mathrm{~mm}$, and 0 and $1.7 \mathrm{~mm}$. 

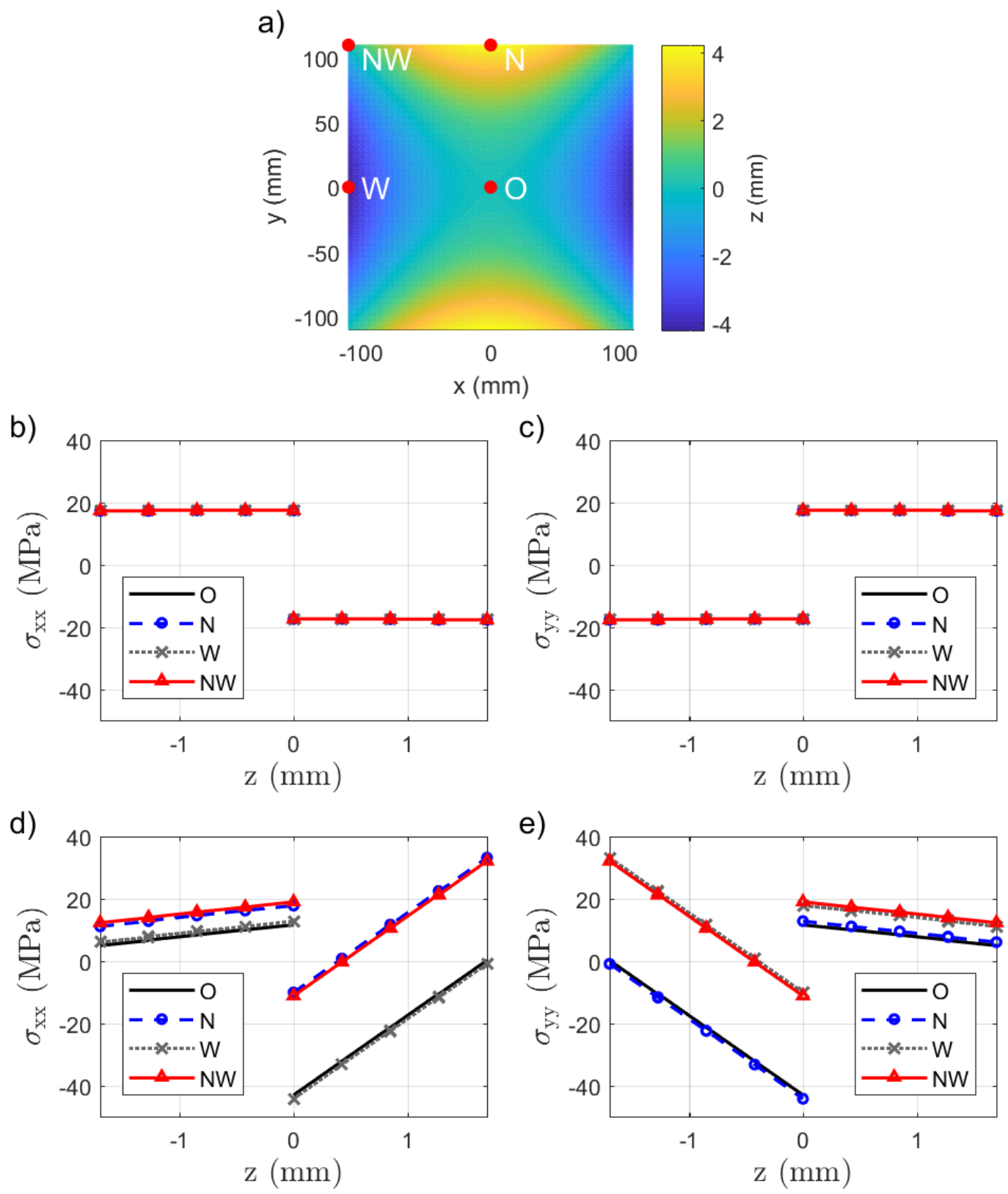

Figure. 10: a) Estimated out of plane displacement $\mathrm{w}$ of the [90_4 0_4] laminate at $20^{\circ} \mathrm{C}$ after demoulding b) and c) Distribution of the in-plane stress component $\sigma \_x x$ and $\sigma \_y y$, respectively, at several locations of the laminate before demoulding d) and e) Distribution of the same stresses components after demoulding.

Before demoulding and along the $x$ direction (Fig 10b), the $90^{\circ}$ plies are homogeneously submitted to a tensile stress reaching a value of $17.9 \mathrm{MPa}$. The $0^{\circ}$ plies are on the contrary submitted to a compressive 
stress of identical intensity. An opposite distribution is found in the y direction, as the $90^{\circ}$ plies are submitted to a compressive stress of $-17.9 \mathrm{MPa}$ and the $0^{\circ}$ to a tensile stress of the opposite value. As the composite cools, the plies tend to thermally shrink along their in-plane transversal direction as the coefficient of thermal expansion is higher along this direction compared to the longitudinal one (Fig. 7). Therefore, the $90^{\circ}$ plies tend to shrink along the $x$ direction. However, as the $0^{\circ}$ plies are stiffer along this direction, the $90^{\circ}$ plies thermal strains are partially blocked by these latter which leads to a tensile stress in the $90^{\circ}$ plies. On the contrary, the $0^{\circ}$ plies are submitted to a compressive stress due to the same mechanism. The same analysis can be drawn along the $y$ direction (Fig. 10c), where the $0^{\circ}$ plies thermal strains are blocked by the $90^{\circ}$ plies. This leads to a tensile stress state in the $0^{\circ}$ plies and a compressive on in the $90^{\circ}$ plies, with the same stresses intensity as previously described.

After demoulding, the previously accumulated stresses distribution generates bending moments along both directions, which leads to the saddle-like shape as the plate is free to deform (Fig. 10a). This relaxes a part of the residual stresses, which modifies the stresses distribution. These ones are no longer homogeneous within plies of identical orientation, neither through the thickness of the plate nor in the $x y$ plane. Along the $x$ direction (Fig 10d), the $90^{\circ}$ plies are submitted to a tensile stress ranging between 6.4 and 19.4 $\mathrm{MPa}$. The $0^{\circ}$ plies are submitted to a compressive stress at $z=0 \mathrm{~mm}$ and to a tensile or nearly nil stress on the outer surface $(z=1.7 \mathrm{~mm})$. The extremal stress values highly depend on the inplane location and are nearly identical for the couples $\{O, W\}$ and $\{N, N W\}$. The minimum and maximum values are respectively of -45.2 MPa and -1.07 MPa for the first couple and of -11.4 MPa and 32.8 MPa for the second couple. An opposite distribution can be found along the $y$ direction. Indeed, the $0^{\circ}$ plies are all submitted to a tensile stress state which amplitude ranges between 6.4 and 19.4 MPa. The $90^{\circ}$ plies are submitted to a compressive stress at $z=0 \mathrm{~mm}$ and to a tensile or nearly nil stress on the lower surface of the laminate $(z=-1.7 \mathrm{~mm})$. The extremal values once again depend on the in-plane location and are nearly identical for the couples $\{O, N\}$ and $\{W, N W\}$. The minimum and maximum values are respectively of -45.2 MPa and -1.07 MPa for the first couple and of -11.4 MPa and 32.8 MPa for the second one. 
From the stresses distribution given in the global coordinate system in Fig. 10 b, c, d and e, it is possible to extract the stresses component in the local coordinate system of each ply and more precisely the stress component in the in-plane direction perpendicular to the fibres $\sigma_{22}$. It corresponds to $\sigma_{x x}$ and to $\sigma_{y y}$ for the $90^{\circ}$ and $0^{\circ}$ plies, respectively. This stress component is indeed the most likely to lead to fibre-matrix decohesion [34] and must be closely monitored to prevent the development of microcracks during manufacturing. Indeed, the composite material strength is often lower along the in-plane direction transversal to the fibres. Fig. 11a therefore represents the through-thickness distribution of this stress component at the locations $O$ and $N W$ estimated at $20^{\circ} \mathrm{C}$, both inside the mould and when the plate is free to deform. These two locations correspond to the extremal values of the stress state.
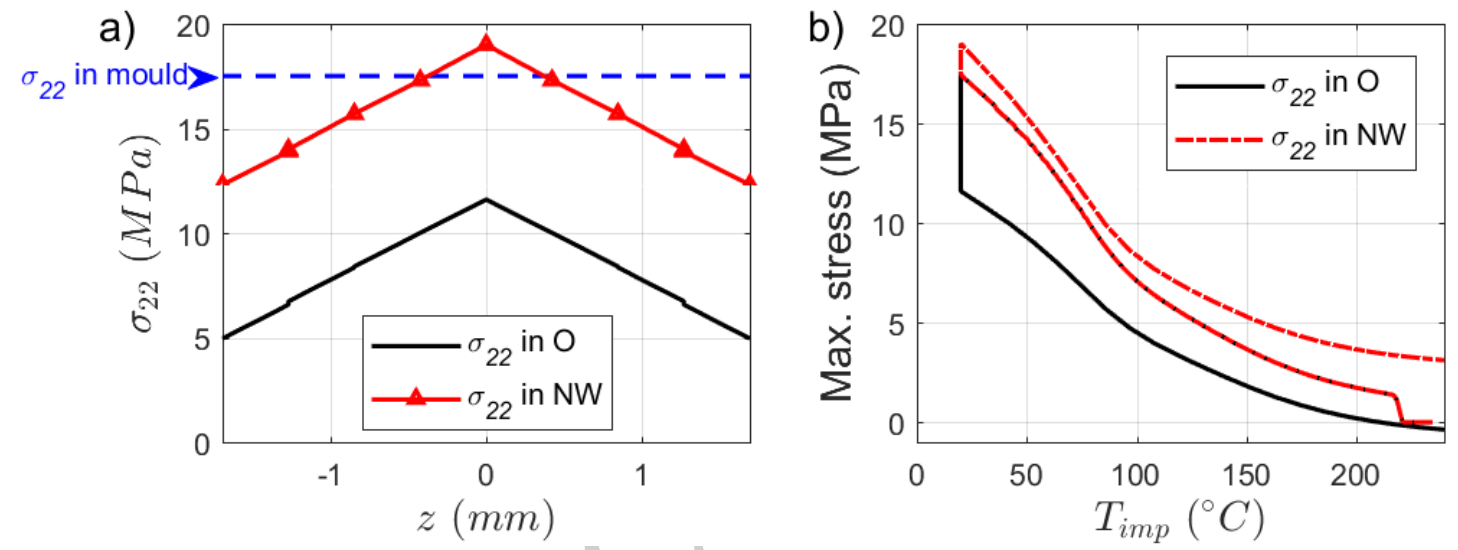

Figure. 11: a) Through-thickness distribution of the stress component transversal to the fibres direction $\sigma \_22$ estimated at $20^{\circ} \mathrm{C}$ at locations $\mathrm{O}$ and NW, both in mould and out of the mould b) Evolution of the maximum value of $\sigma \_22$ through the thickness of the laminate at locations $\mathrm{O}$ and $\mathrm{NW}$ as a function of the imposed temperature $\mathrm{T} \_$imp.

It appears that both plies are submitted to a tensile stress state along this direction. The minimum value is found on the external plies at $z=-1.7$ and $z=1.7 \mathrm{~mm}$ where $\sigma_{22}$ reaches 5.3 MPa and 12.8 MPa in $O$ and $N W$ respectively, and the maximum value $\sigma_{22}$ Max is located at the centre of the laminate with a value of 11.9 MPa and 19.4 MPa in $O$ and $N W$ respectively. The evolution of this maximum value is plotted versus the imposed temperature $T_{i m p}$ in Fig. $11 \mathrm{~b}$. The values of $\sigma_{22}$ Max are nil when the temperature is higher than the peak crystallization temperature, which corresponds to the modelled SFT of the material. Once the crystallization starts, the maximum stress values increase due to the crystallization shrinkage 
and the development of the thermomechanical properties of the composite. Further cooling leads to a non-linear increase of the stress intensity, until it reaches $17.9 \mathrm{MPa}$ at $20^{\circ} \mathrm{C}$. This nonlinear evolution is attributed to the complex evolution of the material stiffness and coefficients of thermal expansion over the considered temperature range (Fig. 3). Moreover, a slope change appears for both locations around $70^{\circ} \mathrm{C}$ which is attributed to the rise in mechanical rigidity of the material as the temperature approaches the glass transition temperature $T_{g}$. This is explained by Eq. 17, where the accumulated stress increment comes not only from the evolution of the mechanical stiffness or of the coefficient of thermal expansion, but from the product of both properties. The glass transition temperature of the material was monitored thanks to the DMA experiments performed in [24]. This led to $T_{g}=63 \pm 1^{\circ} \mathrm{C}$.

When the part is released at $20^{\circ} \mathrm{C}$, the stress intensity in $O$ decreases to $11.9 \mathrm{MPa}$ whereas the one in $N W$ slightly increases to 19.4 MPa. This is due to the release of the curvatures of the part, which alters the residual stresses and strains fields. Then, increasing the temperature lead to a decrease of the stresses intensity, which nullifies in $O$ at $211^{\circ} \mathrm{C}$. It can be noted that the maximum stress in NW does not nullifies, even when the curvature tends to zero at $216^{\circ} \mathrm{C}$ or if the plate is heated at a higher temperature of, for example, $240^{\circ} \mathrm{C}$. This is due to the residual stresses accumulated during the cooling of the plate. These stresses accumulate when the part is forced to remain flat. They partly relax when the plate is released from the mould and lead to a heterogeneous distribution of the stresses in the laminate (Fig. 10 $\mathrm{d}$ and e) when the part deforms. Two more simulations were run to emphasize this phenomenon: one where the laminate out-of-plane displacement are prohibited during both the cooling and re-heating (referred to as the 'blocked' situation) and one where they are free to developed during these two phases (referred to as the 'free' situation). The evolution with the temperature of the maximum transversal stresses for both situations in points $\mathrm{O}$ and NW are represented in Fig. 12a, together with the evolutions obtained previously and referred to as the 'Base’ situation. 

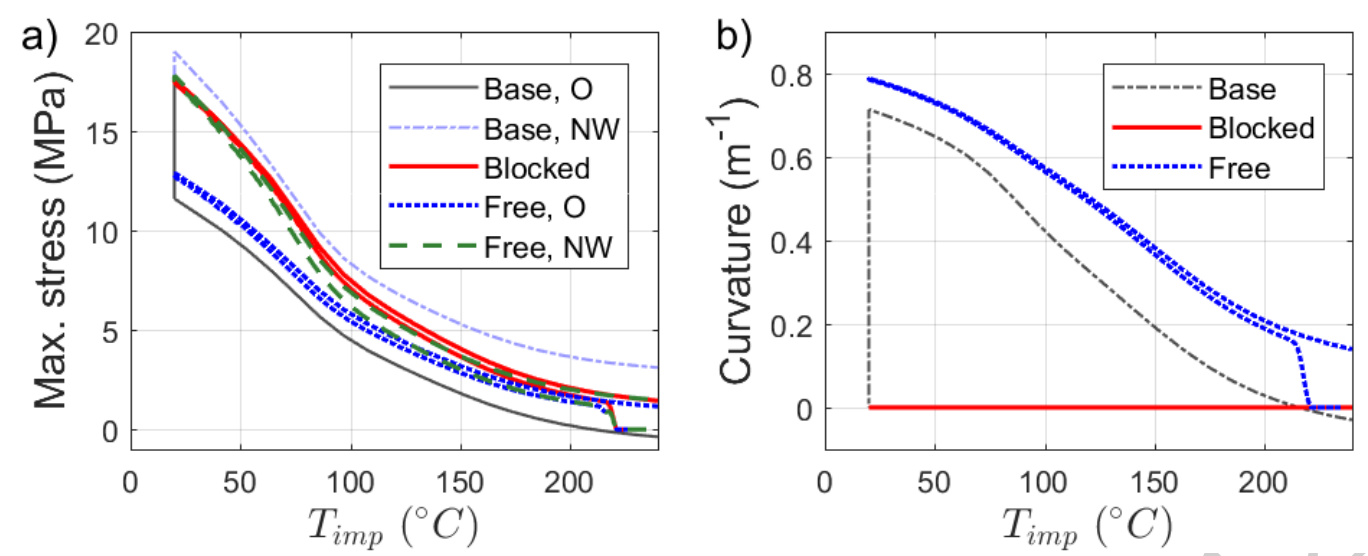

Figure 12: a) Evolution of the estimated maximal stresses in points $\mathrm{O}$ and NW in the 'Base', 'Blocked' and 'Free' situations b) Evolution of the estimated curvature in the 'Base', 'Blocked' and 'Free' situations.

For all three situations and at the two considered points $\mathrm{O}$ and $\mathrm{NW}$, the stresses start to accumulate once the temperature is lower than the SFT. A first rise is observed from $220^{\circ} \mathrm{C}$ to $210^{\circ} \mathrm{C}$ due to the crystallization shrinkage and the development of the mechanical properties of the material. The 'Free' stresses in points $\mathrm{O}$ and NW are however lower than the ones obtained in the 'Base' and 'Blocked' situations. The first ones reach $1.25 \mathrm{MPa}$ and the second ones $1.5 \mathrm{MPa}$ at $210^{\circ} \mathrm{C}$. This is attributed to the fact that the part is free to deform, leading to stress relaxation through the development of curvatures. This is evidenced by the evolution of the 'Free' curvature depicted in Fig. 12b together with the 'Base' and the 'Blocked' curvatures. During crystallization, the 'Free' curvature highly increases from $0 \mathrm{~m}^{-1}$ at $220^{\circ} \mathrm{C}$ to $0.165 \mathrm{~m}^{-1}$ at $210^{\circ} \mathrm{C}$. This deformation is 'locked' in the 'Base' and 'Blocked' situations, leading to more important stresses.

During further cooling, the 'Blocked' stresses are the same in both points $\mathrm{O}$ and NW and they are equal to the ones obtained in the 'Base' situation as the laminate out-of-plane displacements are blocked in both situations. The 'Free' stresses are different during this cooling phase. Indeed, the NW point maximal stress nearly follows the 'Base' and 'Blocked' situations stresses, reaching $17.6 \mathrm{MPa}$ at $20^{\circ} \mathrm{C}$, but the $\mathrm{O}$ point maximal stress is lower and reaches only $12.8 \mathrm{MPa}$ at $20^{\circ} \mathrm{C}$. This is also attributed to the possibility for the laminate to deform freely. The curvature in the 'Free' situation at $20^{\circ} \mathrm{C}$ reaches 0.788 $\mathrm{m}^{-1}$, which is $10 \%$ higher than the curvature obtained in the 'Base' situation. The difference in the 
estimated stresses between the 'Base' and the 'Free' situations will therefore be blocked in the material during the cooling of the laminate in the 'Base' situation, and only partly relaxed when the laminate is released from the mould at $20^{\circ} \mathrm{C}$. This leads to the heterogeneous stresses distribution previously discussed in Fig. 11.

During re-heating, the 'Blocked' and 'Free' stresses nearly follow the same evolution as experienced during cooling from $20^{\circ} \mathrm{C}$ to $210^{\circ} \mathrm{C}$. The slight differences come from the presence of temperature gradients during cooling which are neglected during re-heating (see section 4.2). Simulations run by neglecting temperature gradients during cooling led to identical stresses evolution during cooling and re-heating. Further re-heating at the SFT of $220^{\circ} \mathrm{C}$ does not lead to an annulation of the stresses in the 'Blocked' and 'Free' situations (Fig. 12a) and of the curvature in the 'Free' situation (Fig. 12b) because the PA66 matrix does not melt at this temperature. The temperature at which these stresses might vanish will therefore be the melting temperature, which was estimated around $230^{\circ} \mathrm{C}$ by Faraj [3] but is not accounted for in the developed model. For all the situations, the stresses and curvature would therefore be null for temperatures higher than the melting temperature of the PA66 matrix. If the melting of the matrix is neglected, one can observe that the temperature at which the 'Free' curvature vanish would be at a temperature higher than the crystallization temperature (Fig. 12b). The same behaviour has been observed in the case of thermoset composites, where the ASFT corresponds to a temperature higher than the cure temperature due to the chemical shrinkage occurring during cure [35-37].

\subsection{Discussion on the SFT}

Experimentally, from sections 3.1 and 3.2, the Apparent Stress Free Temperature for the manufactured asymmetric composite strips and plates was found at $193^{\circ} \mathrm{C}$ and $190^{\circ} \mathrm{C}$, respectively. It corresponds to the temperature at which the curvatures of the part nullify. The crystallization peak temperature $T_{P C}$ for this material was estimated at $222^{\circ} \mathrm{C}$ under the cooling rate used to manufacture the composite plates. This leads to a difference of approximately $30^{\circ} \mathrm{C}$ between $T_{P C}$, which is considered as the SFT [5], and the ASFT. 
Numerically, the imposed SFT in the thermo-mechanical model was also considered as the TPC, which value was also set to $T_{P C}=222^{\circ} \mathrm{C}$. During reheating, the temperature at which the curvature of the laminate nullifies was obtained at ASFT $=216^{\circ} \mathrm{C}$. The difference between the SFT and the ASFT is explained by the heterogeneous distributions of the residual stresses obtained after demoulding the part, when the curvatures are free to develop. It appears that, despite the fact that the curvature is null at $216^{\circ} \mathrm{C}$, the stresses in the composite laminate do not vanish but simply equilibrate and lead to this null curvature. This is clearly obtained in a symmetric laminate, in which the stresses are theoretically considered to balance and lead to a flat laminate even though important residual stresses might be present. A simulation was performed on a $\left[90_{2} 0_{2}\right]_{s}$ symmetric laminate. The predicted stresses in $\mathrm{O}$ and NW were the same as in the 'Blocked' situation for the $\left[90_{4} 0_{4}\right]$ laminate, but this symmetric laminate remained flat even if it was released from the mould at $20^{\circ} \mathrm{C}$.

The difference between the experimentally and numerically obtained ASFT might be due to several causes. First, the curvatures were measured only up to $180^{\circ} \mathrm{C}$ due to the limitation of the climate chamber used to perform the experiments. The real curvature might evolve non-linearly with temperature for further heating, until reaching a null value at a higher temperature than the current ASFT, as was observed in the case of carbon fibre reinforced PEEK in [12]. The difference between the experimental and computed ASFT might also come from possible stresses relaxation. This happens at temperatures higher than the glass transition temperature of the material [12] and can be accounted for by using a visco-elastic constitutive law.

\subsection{Comparison with the linear approach}

The modified lamination theory developed by Hyer [20,21] has never been applied to the study of a semi-crystalline thermoplastic composite. Moreover, the application of this method to the investigation of the behaviour of composites during cooling involved constant mechanical properties over the whole cooling. In the following, three degraded models will be considered, which will either consider constant mechanical properties (i.e. corresponding to the properties identified at $25^{\circ} \mathrm{C}$ ), or linear displacementstrain relations (i.e. corresponding to the CLT), or both. Each model is described in Table 3. The 
evolution of the predicted curvature $b$ with the different models is represented in Fig. 13a, together with the ones obtained with the developed model (named "Dev.”) and the measured curvatures $b$ and $-a$.

Table 3: Description of the compared models

Model Constant properties Linear strains

\begin{tabular}{ccc}
\hline Dev. & 0 & 0 \\
Const. & 1 & 0
\end{tabular}

Lin. $\quad 0 \quad 1$

$\begin{array}{lll}\text { Const. Lin. } & 1 & 1\end{array}$

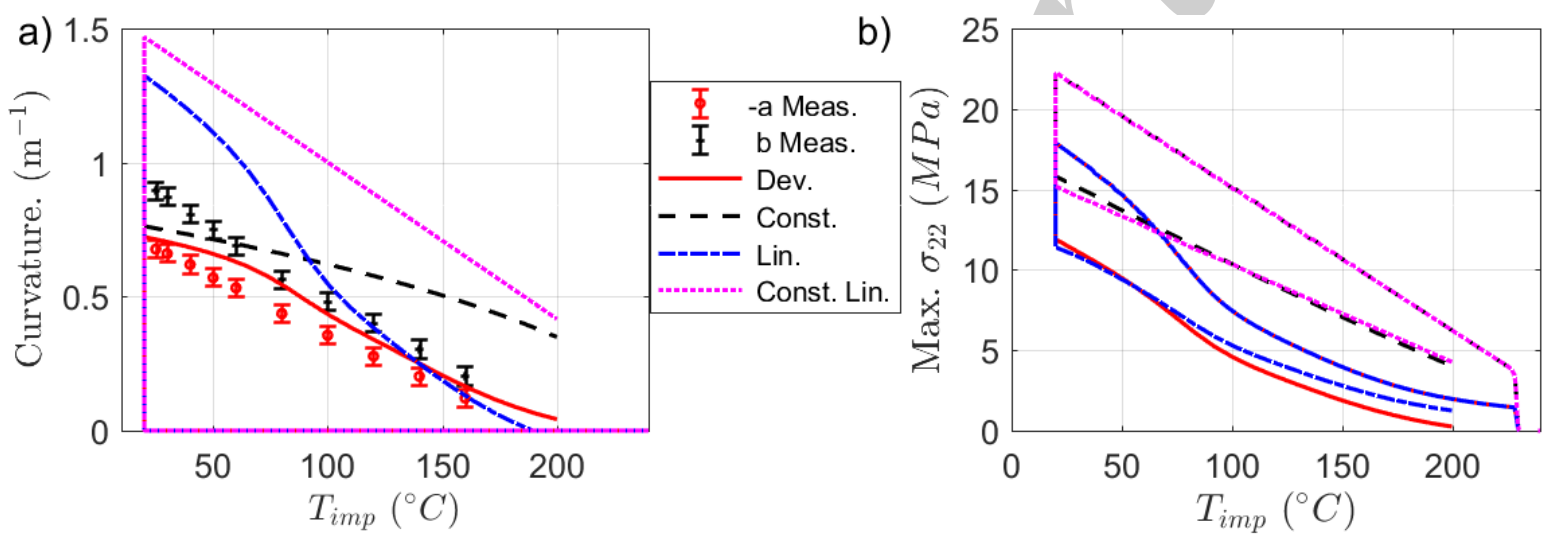

Figure. 13: a) Evolution of the curvatures from the measurement and the four different models b)

Estimated evolution of the maximum transversal stress $\sigma_{-} 22 \mathrm{Max}$ at the centre location $\mathrm{O}$ from the different models.

For all the models, the curvature is nil during cooling and appears when the plate is released from the mould. At room temperature, the initial curvature estimated by the modified CLT model with constant properties (the "Const." one) is close to the measured curvature and to the one predicted by the developed model (the "Dev." one). Indeed, the estimated curvature reaches $0.763 \mathrm{~m}^{-1}$ when the developed model led to $0.717 \mathrm{~m}^{-1}$. The two models involving the CLT (the "Lin.” and "Const. Lin.” ones) overestimate the curvature as they lead to values of 1.325 and $1.468 \mathrm{~m}^{-1}$, respectively. During heating and without surprise, the curvature predicted through the "Const. Lin.” model evolves linearly 
with the temperature from 20 to $200^{\circ} \mathrm{C}$. Even though the predicted slope seems close to the experimentally observed one, it still overestimates the measured curvature with an offset comprised between 0.45 and $0.77 \mathrm{~m}^{-1}$. The curvature estimated with the "Lin.” model evolves non-linearly with the temperature and well reproduces the experimentally measured curvature at high temperature (from 130 to $200^{\circ} \mathrm{C}$ ). The curvature obtained between room temperature and the end of the glass transition (around $100^{\circ} \mathrm{C}$ ) however still overestimates the measured ones. Finally, the curvature estimated with the modified CLT with constant properties (the “Const.” model) overestimates the curvatures at high temperature, as its values tend to the "Const. Lin.” values when temperature approaches $200^{\circ} \mathrm{C}$.

The evolution of the maximum value $\sigma_{22}$ Max computed in the centre of the laminate $O$ from the different models is represented in Fig. 13b. It appears both models with constant properties lead to approximately the same stress intensity evolution. The same analysis can be drawn from the two models with temperature dependent properties. As a consequence, the analysis of the results will be performed by grouping these models. For the different models, the stresses are nil until the peak crystallization temperature, i.e. $230^{\circ} \mathrm{C}$. It then sharply rises during crystallization and this increase is higher for constant properties models as the involved moduli are higher than with temperature dependent properties. At the end of crystallization, the constant properties models lead to a value of $3.86 \mathrm{MPa}$, when the temperature dependent ones lead to 1.46 MPa. During further cooling, the stress intensity increases linearly with the temperature when constant properties are considered. The temperature dependent properties models lead to non-linear evolution of the stress due once again to the temperature dependence of the moduli exhibited in Fig. 3. At the end of cooling and when the part is still in the mould, the predicted stress intensity reaches 22.2 MPa and 17.9 MPa for the constant and temperature dependent properties, respectively. When the part is released, these levels decrease to approximately 15.5 and $11.7 \mathrm{MPa}$, respectively. The following heating leads to a decrease in all predicted stresses. This decrease appears to evolve linearly with temperature for the constant properties models, and non-linearly for the temperature dependent ones.

From these observations on the curvatures and stresses estimation it appears that firstly the "Lin." and "Const. Lin." models are unable to accurately predict the evolution of the curvature as both highly 
overestimate them at room temperature, with a factor comprised between 1.4 and 2.2. The use of such model would therefore lead to non-negligible errors in the estimation of the strains state of the part. Secondly, the models involving constant properties (i.e. the "Const.” and "Const. Lin.” models) do not take into account the development of the mechanical properties of the composite as it cools. That way, they might overestimate the stresses state during the cooling, even though the curvatures predicted at room temperature for the "Const." model are close to the developed model results. Moreover, they do not permit a fine description of the material behaviour around the glass transition temperature $T_{g}$. For these reasons, the developed model seems well adapted for the study of thermoplastic composite material asymmetric laminates during cooling.

\section{Conclusions and perspectives}

The measurement and prediction of residual strains during the cooling of glass fibre reinforced polyamide 66 asymmetric composite plates has been proposed in the present study. The measurement of the curvature of $\left[90_{4} 0_{4}\right]$ plates at different temperatures was performed thanks to a digital image correlation system. The evolution of the curvature indicates that the apparent stress free temperature of the composite is close to $200^{\circ} \mathrm{C}$, which corresponds to the end of crystallization temperature. Based on these observations and on the characterization of the thermomechanical properties of the involved material investigated in a previous study [24], a thermomechanical model was developed to predict the strains and stresses states of composite thin plates during cooling. This model is based on the modified laminate theory, which is adapted for the first time to the study of a thermoplastic composite material during cooling. The mechanical model accounts for the development of the material thermomechanical properties during cooling, as well as thermal expansion and crystallization shrinkage. The temperature and crystallization gradients through the thickness of the part are computed according to a coupled model solved thanks to a finite difference scheme. Both models were validated by comparing their results with experimentally obtained ones, which showed an excellent agreement. It has to be noted that by considering a Stress Free Temperature corresponding to the peak crystallization temperature, which is commonly considered for semi-crystalline matrix composites, the curvature of the plate tend to a nil 
value at a lower temperature called the Apparent SFT. Difference between the SFT and the Apparent SFT reaches $30^{\circ} \mathrm{C}$, both experimentally and with the developed model. The curvature and stresses intensity obtained thanks to the developed model were then compared with models considering either constant thermomechanical properties and/or linear displacement-strain relations. These degraded models might overestimate the curvatures by up to $105 \%$ and the stresses by up to $33 \%$ at room temperature. This comparison demonstrates the ability of the developed model to reproduce the strains and stresses states of the studied part compared to the Classical Lamination Theory (CLT) and the need to account for the actual evolution of the thermomechanical properties during cooling. Finally, the impact of the fibre volume fraction and the cooling rate on the curvature and stresses level is discussed. Even if the fiber volume fraction has a non-negligible impact on the curvature of the part, it appears that this parameter only slightly modifies the stresses intensity. The cooling rate has a negligible impact on both the curvatures and stresses, as it leads to less than $2.6 \%$ variation when the cooling rate varies from -2 to $-200 \mathrm{~K} \cdot \mathrm{min}^{-1}$.

This study demonstrated the ability of the developed model to predict the strains state of thin composite laminates during cooling. However, it is dedicated to the study of the stresses and strains states at a macroscopic scale as each ply is considered as a homogeneous material. A deeper insight in the estimation of the stresses distribution at a finer scale (i.e. the constituents scale) would improve the understanding of the development of residual stresses during the cooling of thermoplastic composite parts. By estimating the stresses distribution at the fibres scale, it would also be possible to understand the development of microcracks at this scale as it still represents a scientific challenge today. Finally, another improvement which would allow for a better description of the composite states concerns the use of a visco-elastic constitutive law to describe the mechanical behaviour of the composite as it cools. This would permit to account for possible stresses relaxation, which mainly occurs when the temperature is higher than the glass transition temperature of the matrix. 


\section{Acknowledgements}

This study is part of the COMPETH project supported and funded by IRT Jules Verne (French Institute in Research and Technology in Advanced Manufacturing, Technologies for Composite, Metallic and Hybrid Structures). The authors wish to associate the industrial partners of this project; respectively Airbus Group, Airbus Group Innovations, Daher and Solvay. The authors also wish to thank Fahmi Alila from Capacités for his helpful advices concerning the use of the image correlation system.

\section{References}

[1] K. Friedrich, A.A. Almajid, Manufacturing aspects of advanced polymer composites for automotive applications, Appl. Compos. Mater. 20 (2013) 107-128.

[2] G. Cazaux, Faisabilité des procédés LCM pour l'élaboration de composites renfort continu à matrice thermoplastique polyamide, PhD Thesis, Université du Havre, France, 2016.

[3] J. Faraj, Analyse thermocinétique de la cristallisation en milieu confiné d'un composite à base d’une résine thermoplastique (Polyamide 66), PhD Thesis, Université de Nantes, France, 2016.

[4] J. Faraj, N. Boyard, B. Pignon, J.L. Bailleul, D. Delaunay, G. Orange, Crystallization kinetics of new low viscosity polyamides 66 for thermoplastic composites processing, Thermochim. Acta. 624 (2016) 27-34. doi:10.1016/j.tca.2015.11.025.

[5] P.P. Parlevliet, H.E.N. Bersee, A. Beukers, Residual stresses in thermoplastic composites-A study of the literature-Part I: Formation of residual stresses, Compos. Part A Appl. Sci. Manuf. 37 (2006) 1847-1857. doi:10.1016/j.compositesa.2005.12.025.

[6] I. Baran, K. Cinar, N. Ersoy, R. Akkerman, J.H. Hattel, A Review on the Mechanical Modeling of Composite Manufacturing Processes, Arch. Comput. Methods Eng. 24 (2017) 365-395. doi:10.1007/s11831-016-9167-2.

[7] P.P. Parlevliet, H.E.N. Bersee, A. Beukers, Residual stresses in thermoplastic composites - a study of the literature. Part III: Effects of thermal residual stresses, Compos. Part A Appl. Sci. Manuf. 38 (2007) 1581-1596. doi:10.1016/j.compositesa.2006.12.005.

[8] N. Boyard, Heat Transfer in Polymer Composite Materials: Forming Processes, ISTE Ltd, London, 2016.

[9] M. Avrami, Kinetics of phase change. I General theory, J. Chem. Phys. 7 (1939) 1103-1112.

[10] K. Nakamura, T. Watanabe, K. Katayama, T. Amano, Some aspects of nonisothermal crystallization of polymers. I. Relationship between crystallization temperature, crystallinity, and cooling conditions, J. Appl. Polym. Sci. 16 (1972) 1077-1091.

[11] N. Zobeiry, A. Forghani, C. Li, K. Gordnian, R. Thorpe, R. Vaziri, G. Fernlund, A. Poursartip, Multiscale characterization and representation of composite materials during processing., Philos. Trans. A. Math. Phys. Eng. Sci. 374 (2016) 43-72. 
[12] J.A. Barnes, G.E. Byerly, The formation of residual stresses in laminated thermoplastic composites, Compos. Sci. Technol. 51 (1994) 479-494.

[13] G. Jeronimidis, a. T. Parkyn, Residual Stresses in Carbon Fibre-Thermoplastic Matrix Laminates, J. Compos. Mater. 22 (1988) 401-415. doi:10.1177/002199838802200502.

[14] S.-W. Hsiao, N. Kikuchi, Numerical analysis and optimal design of composite thermoforming process, Comput. Methods Appl. Mech. Eng. 177 (1999) 1-34. doi:10.1016/S00457825(98)00273-4.

[15] A. Trende, B.T. Aström, G. Nilsson, Modelling of residual stresses in compression moulded glass-mat reinforced thermoplastics, Compos. Part A Appl. Sci. Manuf. 31 (2000) 1241-1254. doi:10.1016/S1359-835X(00)00078-6.

[16] T.J. Chapman, J.W. Gillespie, R.B. Pipes, J.-A.E. Manson, J.C. Seferis, Prediction of ProcessInduced Residual Stresses in Thermoplastic Composites, J. Compos. Mater. 24 (1990) 616-643. doi:10.1177/002199839002400603.

[17] P. Sunderland, W. Yu, J.-A.E. Manson, A thermoviscoelastic analysis of process-induced internal stresses in thermoplastic matrix composites, Polym. Compos. 22 (2001) 579-592. doi:10.1002/pc.10561.

[18] W.E. Lawrence, J.C. Seferis, Material response of a semicrystalline thermoplastic polymer and composite in relation to process cooling history, Polym. Compos. 13 (1992) 86-96.

[19] M.M. Domb, J.S. Hansen, The effect of cooling rate on free-edge stress development in semicrystalline thermoplastic laminates, J. Compos. Mater. 32 (1998) 361-386.

[20] M.W. Hyer, Calculations of the Room-Temperature Shapes of Unsymmetric Laminates, J. Compos. Mater. 15 (1981) 296.

[21] M.W. Hyer, The Room-Temperature Shapes of Four-Layer Unsymmetric Cross-Ply Laminates, J. Compos. Mater. 16 (1982) 318-340. doi:10.1177/002199838201600406.

[22] P.P. Parlevliet, H.E.N. Bersee, A. Beukers, Residual stresses in thermoplastic composites-A study of the literature-Part II: Experimental techniques, Compos. Part A Appl. Sci. Manuf. 38 (2007) 651-665. doi:10.1016/j.compositesa.2006.07.002.

[23] Y. Abou Msallem, Caractérisation thermique et mécanique d'un matériau composite aéronautique pendant le procédé d'élaboration - Contribution à l'estimation des contraintes résiduelles, Thèse de Doctorat, Ecole Centrale de Nantes, 2008.

[24] M. Peron, F. Jacquemin, P. Casari, G. Orange, J.-L. Bailleul, N. Boyard, Thermomechanical characterization of a low viscosity PA66 thermoplastic matrix and associated continuous glass fibre composite under processing conditions, J. Compos. Mater. 53 (2019) 3169-3186.

[25] A.C. Palerosi, S.F.M. de Almeida, Thermoelastic evaluation of composite laminates using digital imaging processing, Compos. Part A Appl. Sci. Manuf. 38 (2007) 2283-2293. doi:10.1016/j.compositesa.2006.12.004.

[26] M.W. Hyer, Some Observations on the Cured Shape of Thin Unsymmetric Laminates, J. Compos. Mater. 15 (1981) 175-194. doi:10.1177/002199838101500207.

[27] D. Joh, K.Y. Byun, J. Ha, Thermal residual stresses in thick graphite/epoxy composite laminatesUniaxial approach, Exp. Mech. 33 (1993) 70-76. doi:10.1007/BF02322554.

[28] A. Hamamoto, M.W. Hyer, Non-Linear Temperature-Curvature Relationships for Unsymmetric Graphite-Epoxy Laminates, 23 (1987) 919-935. doi:10.1016/0020-7683(87)90087-4. 
[29] W.J. Jun, C.S. Hong, Effect of residual shear strain on the cured shape of unsymmetric cross-ply thin laminates, Compos. Sci. Technol. 38 (1990) 55-67. doi:10.1016/0266-3538(90)90071-C.

[30] L.J.B. Peeters, P.C. Powell, L. Warnet, Thermally-Induced Shapes of Unsymmetric Laminates, J. Compos. Mater. 30 (1996) 603-624. doi:10.1177/002199839603000504.

[31] M. Cho, M.-H. Kim, H.S. Choi, C.H. Chung, K.-J. Ahn, Y.S. Eom, A Study on the RoomTemperature Curvature Shapes of Unsymmetric Laminates Including Slippage Effects, J. Compos. Mater. 32 (1998) 460-482. doi:10.1177/002199839803200503.

[32] M. Gigliotti, J. Molimard, F. Jacquemin, A. Vautrin, On the nonlinear deformations of thin unsymmetric 0/90 composite plates under hygrothermal loads, Compos. Part A Appl. Sci. Manuf. 37 (2006) 624-629. doi:10.1016/j.compositesa.2005.05.003.

[33] A. Benkeddad, M. Grédiac, A. Vautrin, On the transient hygroscopic stresses in laminated composite plates, Compos. Struct. 30 (1995) 201-215.

[34] C.T. Herakovich, Mechanics of fibrous composites, John Wiley \& Sons, 1998.

[35] M.R. Wisnom, M. Gigliotti, N. Ersoy, M. Campbell, K.D. Potter, Mechanisms generating residual stresses and distortion during manufacture of polymer-matrix composite structures, Compos. Part A Appl. Sci. Manuf. 37 (2006) 522-529. doi:10.1016/j.compositesa.2005.05.019.

[36] M. Gigliotti, M.R. Wisnom, K.D. Potter, Loss of bifurcation and multiple shapes of thin [0/90] unsymmetric composite plates subject to thermal stress, Compos. Sci. Technol. 64 (2004) 109128. doi:10.1016/S0266-3538(03)00213-6.

[37] K.D.P. M. Gigliotti, M.R. Wisnom, Development of curvature during the cure of AS4/8552 [0/90] unsymmetric composite plates, Compos. Sci. Technol. 63 (2003) 187-197. 